\title{
Water droplet calibration of the Cloud Droplet Probe (CDP) and in-flight performance in liquid, ice and mixed-phase clouds during ARCPAC
}

\author{
S. Lance ${ }^{1,2}$, C. A. Brock ${ }^{1}$, D. Rogers ${ }^{3}$, and J. A. Gordon ${ }^{4}$ \\ ${ }^{1}$ Earth System Research Laboratory, National Oceanic and Atmospheric Administration, Boulder, CO, USA \\ ${ }^{2}$ Cooperative Institute for Research in Environmental Sciences, University of Colorado, Boulder, CO, USA \\ ${ }^{3}$ National Center for Atmospheric Research, Research Aviation Facility, Broomfield, CO, USA \\ ${ }^{4}$ National Institute of Standards and Technology, Boulder, CO, USA
}

Received: 28 June 2010 - Published in Atmos. Meas. Tech. Discuss.: 26 July 2010

Revised: 12 November 2010 - Accepted: 1 December 2010 - Published: 14 December 2010

\begin{abstract}
Laboratory calibrations of the Cloud Droplet Probe (CDP) sample area and droplet sizing are performed using water droplets of known size, generated at a known rate. Although calibrations with PSL and glass beads were consistent with theoretical instrument response, liquid water droplet calibrations were not, and necessitated a $2 \mu \mathrm{m}$ shift in the manufacturer's calibration. We show that much of this response shift may be attributable to a misalignment of the optics relative to the axis of the laser beam. Comparison with an independent measure of liquid water content (LWC) during in-flight operation suggests much greater biases in the droplet size and/or droplet concentration measured by the CDP than would be expected based on the laboratory calibrations. Since the bias in CDP-LWC is strongly concentration dependent, we hypothesize that this discrepancy is a result of coincidence, when two or more droplets pass through the CDP laser beam within a very short time. The coincidence error, most frequently resulting from the passage of one droplet outside and one inside the instrument sample area at the same time, is evaluated in terms of an "extended sample area" $\left(\mathrm{S} \mathrm{A}_{\mathrm{E}}\right)$, the area in which individual droplets can affect the sizing detector without necessarily registering on the qualifier. $\mathrm{SA}_{\mathrm{E}}$ is calibrated with standardized water droplets, and used in a Monte-Carlo simulation to estimate the effect of coincidence on the measured droplet size distributions. The simulations show that extended coincidence errors are important for the CDP at droplet concentrations even as low as $200 \mathrm{~cm}^{-3}$, and these errors are necessary to explain the trend between calculated and measured LWC observed in liquid and mixed-phase clouds during the Aerosol, Radiation
\end{abstract}

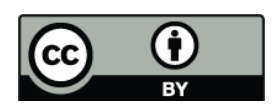

Correspondence to: S. Lance (sara.m.lance@noaa.gov) and Cloud Processes Affecting Arctic Climate (ARCPAC) study. We estimate from the simulations that $60 \%$ oversizing error and 50\% undercounting error can occur at droplet concentrations exceeding $400 \mathrm{~cm}^{-3}$. Modification of the optical design of the CDP is currently being explored in an effort to reduce this coincidence bias.

\section{Introduction}

\subsection{Measurement of cloud particles}

There are limitations to every cloud measurement technique. The wide range of cloud particle sizes $(\sim 1 \mu \mathrm{m}$ to $10 \mathrm{~mm}$ in diameter) and number concentrations $\left(\sim 10^{-5}\right.$ to $\left.10^{3} \mathrm{~cm}^{-3}\right)$ that naturally exist typically necessitates more than one measurement technique or a suite of instruments that are each tuned to specifically detect a subset of the cloud particle population. In situ measurements of individual cloud droplets can be subject to a wide variety of instrument biases, uncertainties and limitations, which are the focus of this paper, specifically as these relate to the performance of a commercial instrument called the Cloud Droplet Probe (CDP) manufactured by Droplet Measurement Technologies, Inc., Boulder, CO, USA.

Measurement uncertainties for droplet concentration and sizing together result in greater uncertainty for higher order products such as liquid water content (LWC, the mass of liquid water in a given atmospheric volume) calculated from the observed cloud droplet size distributions. Comparison to independent observations of LWC is therefore a useful method for testing the accuracy of droplet size distribution measurements, since bulk LWC measurements are typically characterized by different intrinsic uncertainties. To

Published by Copernicus Publications on behalf of the European Geosciences Union. 
accurately calculate LWC, the droplet size distribution must be known even more accurately since LWC is proportional to the third power of droplet size.

A specific challenge for in situ cloud droplet measurements using optical methods is the definition of a sample area, the cross-sectional area within which droplets are detected (perpendicular to the flow velocity), which is constrained by the optical and electronic configuration of the instrument. The sample volume is derived by multiplying the sample area by the flow velocity and the sample duration. Therefore, a bias in the sample area or in the flow velocity translates directly to a bias in measured droplet concentrations and calculated LWC. Hereafter, we refer most often to the sample area rather than the sample volume, since the focus of the paper is on the cloud probe performance.

Although multiple cloud measurements can be used to complement each other using optimal estimation methods (Feingold et al., 2006), it is difficult to find a fair basis for comparison between remote-sensing and in situ cloud observations, and ultimately to use either to validate the other, due to the multiple degrees of freedom between the parameters that each technique measures best. The lack of an objective standard makes the validation of in situ droplet measurements a challenging task, which is not addressed the same way by all researchers. Often, redundant in situ instruments, covering the same cloud particle size range and operating from the same sampling platform, are used to address this problem. However, it is not always possible to reconcile observational differences between the various in situ measurements, which can be quite significant (e.g. McFarquahar et al., 2007; Baumgardner, 1983). Laboratory calibrations are performed to resolve these differences, with the ultimate purpose of distinguishing natural ambient variability from measurement uncertainty.

The sizing performance of in situ cloud probe instruments is typically calibrated in the laboratory by injecting standardized particles directly across the sample area of the open path laser beam. The type of calibration particles used, most often glass beads or polystyrene latex (PSL) spheres, have their own unique response in the instrument. This means that calibration with standardized particles is only the first step. Due to differences in the refractive index between water droplets and the calibration particles, the response of the instrument to water droplets must then be calculated with assumptions about the laser and light-collecting optics. To avoid these assumptions, calibration with water droplets is preferred since ambient cloud droplets are typically dilute aqueous solutions, which are expected to behave optically like pure water droplets (Diehl et al., 2008). Generation of a standardized droplet size and number concentration of water droplets for calibration is not a trivial task. Despite the difficulty, however, it has been shown that such an effort is worthwhile. For instance, the forward scattering spectrometer probe (FSSP) was shown to oversize water droplets of $15-30 \mu \mathrm{m}$ diameter by up to $15 \%$ when using glass beads for calibration (Wendisch et al., 1996), which then leads to as much as a $52 \%$ overestimate in LWC even when the droplet concentration is measured with $100 \%$ accuracy.

An important characteristic of droplet generation methods employed by many researchers (e.g. Nagel et al., 2007; Wendisch et al., 1996; Korolev et al., 1985, 1991; Jonnson and Vonnegut, 1982; Schneider and Hendricks, 1964), is the steady production of droplets one-at-a-time, thereby avoiding coincidence errors, which occur when two or more droplets pass through the sample area at the same time. The droplet generation method employed by Nagel et al. (2007) to evaluate the FSSP utilizes a commercial piezo-electric inkjet device. Taking advantage of the steady production rate of calibration droplets, it is also possible to test the counting efficiency of the cloud probe instrument and to clearly map the sample area.

In the end, however, even these carefully crafted laboratory calibration are not always representative of in situ measurements, as artifacts can arise solely during in-flight operation. It is well known, for instance, that the external geometry of a cloud probe instrument can significantly alter the measured cloud particle size distribution as a result of large droplets and ice crystals shattering, either by direct impaction with the instrument arms extending upstream of the sample volume or by the shear forces as the particles are deflected by the airstream flowing around the probe (Gardiner and Hallet, 1985; Korolev and Isaac, 2005; Field et al., 2006; Heymsfield, 2007; McFarquahar et al., 2007; Jensen et al., 2009). Wind-tunnel studies and computational fluid dynamics simulations can be used to simulate the in-flight environment to evaluate potential problems such as those related to cloud particle shattering, changes to the cloud particle trajectory, or icing of the cloud probe. However, these types of artifacts are very difficult to quantify in a laboratory setting due in large part to the difficulty of continuously generating and transmitting ice crystals with realistic sizes, shapes and concentrations at high velocities upstream of a cloud droplet probe.

In situ LWC measurements from hot-wire probes provide an independent observation for validating measured cloud droplet size distributions from a single aircraft sampling platform. However, hot-wire measurements have their own limitations; e.g. (1) they are limited to non-precipitating conditions, as their sensitivity declines appreciably and unpredictably for droplet sizes above $\sim 40 \mu \mathrm{m}$ due to droplet splattering (Biter et al., 1987; Feind et al., 2000), (2) the collection of small droplets $(<5 \mu \mathrm{m})$ is not $100 \%$ efficient (King et al., 1978), and (3) a percentage of the ice mass present in ice-only or mixed-phase clouds can be mistakenly attributed to liquid water. Thus, while hot-wire LWC measurements and optical cloud probe measurements are complementary to one another and should be flown together whenever possible, careful and detailed laboratory calibrations with water droplets are necessary for fundamental evaluation of a cloud droplet probe. 
Table 1. Instruments on the ARCPAC flights.

\begin{tabular}{llllc}
\hline Instrument Name & Acronym & Method & Range & units \\
\hline $\begin{array}{l}\text { Cloud and Aerosol } \\
\begin{array}{l}\text { Spectrometer } \\
\text { Serial \#: CAS-0708-017 }\end{array}\end{array}$ & CAS & $\begin{array}{l}\text { Forward/Back } \\
\text { Optical Scattering }\end{array}$ & $0.6-50$ & $\mu \mathrm{m}$ \\
\hline $\begin{array}{l}\text { Cloud Droplet Probe } \\
\text { Serial \#: CCP-0703-010 }\end{array}$ & CDP & $\begin{array}{l}\text { Forward } \\
\text { Scattering }\end{array}$ & $3-50$ & $\mu \mathrm{m}$ \\
\hline $\begin{array}{l}\text { Cloud Imaging Probe } \\
\text { Serial \#: CCP-0703-010 }\end{array}$ & CIP & 2-D image & 25-2000 & $\mu \mathrm{m}$ \\
\hline $\begin{array}{l}\text { Precipitation Imaging Probe } \\
\text { Serial \#: PIP-0705-005 }\end{array}$ & PIP & 2-D image & $100-6000$ & $\mu \mathrm{m}$ \\
\hline CSIRO King Probe & King-LWC & Hot-wire & $0.1-6.0$ & $\mathrm{~g} \mathrm{~m}^{-3}$ \\
\hline Johnson-Williams Probe & JW-LWC & Hot-wire & $0.1-6.0$ & $\mathrm{~g} \mathrm{~m}^{-3}$ \\
\hline
\end{tabular}

In this study we use standardized water droplets generated in the laboratory to quantify the uncertainties of the CDP. A further goal of this study is to evaluate the performance of the CDP during airborne operation onboard the NOAA WP-3D during the Aerosol, Radiation, and Cloud Processes affecting Arctic Climate project (ARCPAC, http: //www.esrl.noaa.gov/csd/arcpac/), which took place in the Alaskan Arctic in April 2008, by comparing the measured droplet size distributions with hot-wire LWC measurements. CDP observations in liquid, ice and mixed-phase clouds sampled during ARCPAC are discussed.

\subsection{The ARCPAC campaign}

The ARCPAC field campaign was designed to evaluate the climatic effects of Arctic Haze (Brock et al., 2010), including the indirect effects of aerosols on Arctic clouds. Low level clouds in the Arctic springtime can warm the surface by absorbing in the infrared (Curry and Ebert, 1992; Curry et al., 1993). It is expected that changes in the concentrations of either cloud condensation nuclei or ice nuclei can affect the drop size distribution and even the cloud phase, thereby changing cloud radiative properties (Lubin and Vogelmann, 2006; Garrett and Zhao, 2006). Also of interest is the removal of particles by clouds, especially as deposition of soot and other absorbing aerosols onto snow surfaces can significantly alter the surface albedo (McConnell et al., 2007). In recent years, special interest in both of these processes has been fueled by faster-than-expected warming in the Arctic and an accelerated rate of Arctic seaice melt (Alekseev et al., 2009; Serreze and Francis, 2006). Towards our ultimate goal of understanding the aerosolcloud-interactions in the Arctic, we first evaluate the uncertainties and limitations of the CDP observations obtained during ARCPAC.

\section{Instrumentation}

\subsection{Overview}

Table 1 lists instruments relevant for in situ cloud sampling onboard the NOAA WP-3D during the ARCPAC campaign. During ARCPAC, the in situ cloud probes were mounted below and forward of the port-side wing tip of the NOAA WP$3 \mathrm{D}$, while the LWC probes were mounted along the lower side of the fuselage, well forward of the port-side wing.

The CSIRO King-LWC measurements are an important part of this study, for evaluating the in-flight performance of the CDP. These measurements are corrected by first determining the signal offset in clear-air as a function of the ambient temperature, pressure and true air speed measurements (King et al., 1978, 1981, 1985), where clear-air is identified from the cloud probe measurements. We do not manually correct for baseline drift, as many researchers do, by subtracting a bias determined from linear interpolation between measurements before and after each cloud penetration, thereby forcing the clear-air LWC measurements to zero. Although a bias in the LWC measurements is expected for clouds containing significant ice mass, this type of manual correction is not applied because it is not entirely clear during sustained in-cloud sampling whether the LWC baseline in mixed-phase clouds drifts at a steady rate (for which a linear correction is appropriate) or whether the baseline drift occurs suddenly at intervals when high supercooled liquid mass or high ice mass is encountered. We estimate that the King-LWC measurements during ARCPAC can be biased by as much as $0.08 \mathrm{~g} \mathrm{~m}^{-3}$ in mixed-phase clouds. To limit uncertainties caused by baseline drift and temporary hysteresis following sustained liquid or ice impaction, we do not use King-LWC measurements $<0.1 \mathrm{~g} \mathrm{~m}^{-3}$ in our analysis. 
The JW-LWC probe on the WP-3D aircraft, although reportedly more precise, was found to be much less reliable than the King-LWC probe during ARCPAC; the baseline for the JW-LWC measurements drifted by as much as $0.2 \mathrm{~g} \mathrm{~m}^{-3}$ throughout the campaign without any apparent systematic cause. The JW-LWC measurements are therefore not used.

Both the CIP and PIP (acronyms defined in Table 1) produce images of individual particles by the shadows they cast on a photodiode array as they transit across a laser beam, in a manner similar to the optical array probes used by Korolev et al. (1991). Only measurement of particles $>400 \mu \mathrm{m}$ obtained from the PIP are used to quantify ice crystal concentrations, since this size range has been shown to be least susceptible to ice shattering artifacts (Korolev et al., 2010).

The CAS and the CDP are single-particle instruments that measure the light scattered from a droplet or large particle passing through an open path laser beam. Both the CAS and CDP make use of two photodetectors to constrain the optical sample area. Although the CAS measurement covers a range of sizes that includes the size range of the CDP, we do not report observations from the CAS in this paper. The CAS has been successfully applied in cloud droplet closure studies previously (Fountoukis et al., 2007; Meskhidze et al., 2005; Conant et al., 2004), however, the performance of the CAS used in ARCPAC has not been documented, and preliminary analysis indicates some problems with the measurements, which need to be addressed separately.

While the performance of other single particle forward scattering probes like the CAS and FSSP have been documented in detail in many studies (e.g. Baumgardner and Spowart, 1990; Brenguier et al., 1998; Wendisch et al., 1996; Baumgardner et al., 2001; Nagel et al., 2007), the CDP differs in terms of its optics, electronics and external geometry. Specific aspects regarding the expected performance of the CDP are outlined in the following sections.

\subsection{General operation of the CDP}

The CDP uses a diode laser, with a single mode elliptical Gaussian beam roughly $2 \mathrm{~mm} \times 0.2 \mathrm{~mm}$, to count and size individual water droplets. The laser is maintained at a constant temperature, and the laser current is modulated to obtain constant laser intensity as measured by a photodetector called the "dump spot monitor" (Fig. 1). The CDP used during ARCPAC internally accumulates information about individual droplets and reports binned droplet size distributions over a specified sampling interval. Newer versions of the CDP are capable of storing information about individual droplets, which can significantly aid in measurement interpretation.

\subsection{CDP sample area}

The optical cross section of the laser beam path for which droplets are deemed in-focus, or the qualified sample area $\left(\mathrm{SA}_{\mathrm{Q}}\right)$, is a necessary parameter for quantifying the ambient

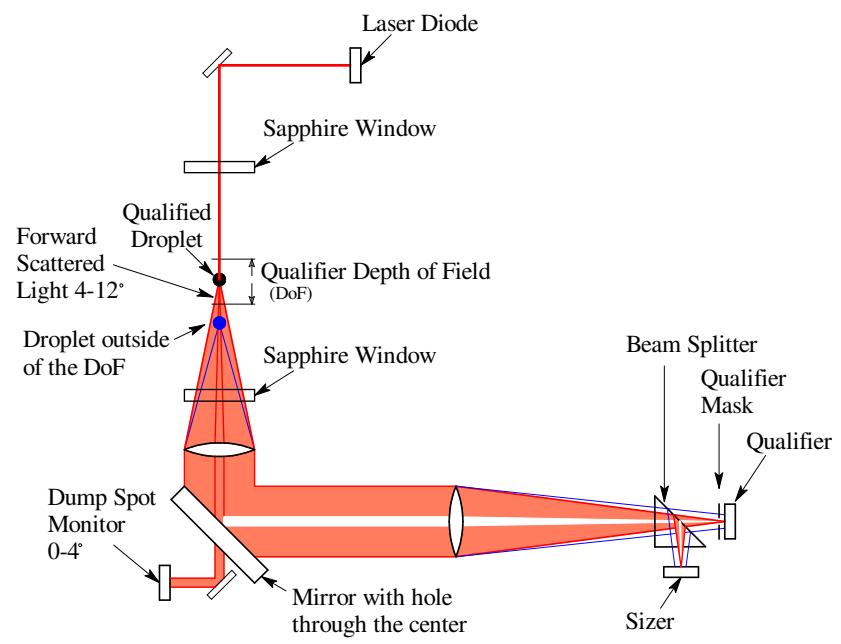

Fig. 1. Optical schematic of the CDP. Light rays colored in red indicate the scattering signal for a droplet within the qualifier DoF, whereas blue light rays indicate a droplet outside of the qualifier DoF. For the qualified droplet, the scattered light is focused through the slit of the qualifier mask, allowing the qualifier signal to be great enough such that the particle is counted.

droplet number concentration. Calibration of $\mathrm{SA}_{\mathrm{Q}}$ has been performed previously for the FSSP using a spinning disk with a wire attached (Nagel et al., 2007) and a pinhole (Brenguier et al., 1998) with fine positioning control. However, calibration of $\mathrm{SA}_{\mathrm{Q}}$ for the CDP has not been previously published, nor have researchers consistently reported the value used for $\mathrm{SA}_{\mathrm{Q}}$ in calculating droplet concentrations from CDP data.

Particles are considered within $\mathrm{SA}_{\mathrm{Q}}$ when they lie within the depth of field (DoF) of the qualifier optics and are therefore in-focus. These qualified particles are a subset of all detected particles. The CDP qualifies a detected particle as either within or outside of $\mathrm{SA}_{\mathrm{Q}}$ with the use of an unmasked photodetector (sizer), a masked photodetector (qualifier) and a comparator circuit. Light scattered by a particle is collected over a range of angles $\sim 4-12^{\circ}$ in the forward direction and then split equally between the qualifier and sizer (Fig. 1). The two signals are amplified, such that the qualifier signal is roughly a factor of two times the sizer signal at the center of the qualifier DoF. The baselines of the two signals are also adjusted slightly, so that electronic noise on the qualifier signal does not mistakenly trigger a counting event. When the qualifier voltage is larger than the sizer voltage, a particle is considered inside the qualifier DoF and is therefore counted. The amplitude of the sizer pulse is then used to determine the size of the droplets within $\mathrm{SA}_{\mathrm{Q}}$, as discussed in the next section.

The qualifier mask of the CDP is a rectangular slit configuration, with long side parallel to the air flow, which is fundamentally different from the optical mask of the original FSSP "annulus" detector (used to qualify whether particles are in the qualifier DoF), which has a masked central region 
that is circular in shape. However, both utilize the same basic principle; when the droplet image is out-of-focus, the image is larger and more diffuse (Burnet and Brenguier, 2002), allowing more or less light to reach the detector, depending on the optical configuration. The original FSSP annulus detector measures a low voltage when the droplet is in-focus (because the in-focus image is almost entirely masked), whereas the CDP qualifier measures a low voltage when the droplet is out-of-focus (because the out-of-focus image is larger than the slit in the qualifier mask, and therefore only a fraction of the total scattered light is detected). The newer FSSP models (e.g. Fast-FSSP and FSSP-300) use an optical mask with a similar shape to the slit in the CDP (Burnet and Brenguier, 2002). The slit configuration limits droplet detection to positions along the centerline of the laser beam where laser intensity is more uniform.

\subsection{CDP droplet sizing}

Because $S A_{Q}$ is within the Rayleigh range of the Gaussian laser beam used by the CDP, the beam approximates a plane wave, and light scattered by a droplet within $\mathrm{SA}_{\mathrm{Q}}$ is therefore expected to follow Mie theory (Bohren and Huffman, 1983). Scattered light from individual droplets is collected over a given range of angles by an unmasked photodetector (i.e. the sizer, Fig. 1), and converted to a digital signal, which is then related to a droplet size. To calibrate the sizer response, particles of known size are injected into the sample area of the CDP. If glass beads or polystyrene latex spheres are used to calibrate the sizer, the response of the CDP to water droplets must be calculated based on the difference in refractive index between water and glass, for instance. The scattering collection angles of the photodetector must be known accurately to apply this technique. Calibrating the CDP with water droplets of known size circumvents this assumption.

\subsection{Sources of uncertainty for the CDP measurement}

The potential sources of error for in situ cloud probe observations result from different mechanisms ranging from optical to electronic, statistical and mechanical in nature. We briefly outline many of these different sources of error for the $\mathrm{CDP}$, which have previously been identified in the evaluation of other forward scattering probes. Brenguier et al. (1998) cover many of these issues in detail.

\subsubsection{Size resolution limits due to Mie resonance}

Droplet sizing by the CDP is limited by discrete binning of measured pulse heights, with a default of 30 bins covering the range from $3-50 \mu \mathrm{m}$. The bins prescribed by the manufacturer are $1 \mu \mathrm{m}$ wide from 3 to $14 \mu \mathrm{m}$, after which they become $2 \mu \mathrm{m}$ wide. Although the bin definitions can be changed in the instrument software, the sizing resolution of the CDP is expected to be fundamentally limited by the nonmonotonic relationship between droplet size and scattered light signal. Mie resonance structure is most pronounced for a single mode laser such as used in the CDP, while a multi-mode laser, as is used in the standard FSSP, can potentially dampen the Mie resonances (Knollenberg et al., 1976). However, the single-mode CDP diode laser $(658 \mathrm{~nm})$ avoids the greater spatial intensity and/or phase inhomogeneity of a multi-mode laser, which can result in a greater broadening of the measured droplet size distribution (Baumgardner et al.,1990) in addition to a shift in the measured mean size (Hovenac and Lock, 1993).

\subsubsection{Spatially heterogeneous sizing response}

The CDP is expected to exhibit a spatially heterogeneous sizing response within the qualified sample area, similar to the FSSP (as reported by Wendisch et al., 1996 and Nagel et al., 2007), which results in broadening of the measured droplet size distribution, regardless of the cause. However the degree of droplet spectral broadening for the CDP measurements is not known. A spatially heterogeneous sizing response can be due to several different factors: (1) a gradient in laser intensities within $\mathrm{SA}_{\mathrm{Q}}$, (2) different light-scattering collection angles for droplets at different positions within $\mathrm{SA}_{\mathrm{Q}}$, and (3) misalignment between the qualifier DoF and the sizer DoF. Limiting $\mathrm{SA}_{\mathrm{Q}}$ to a small region with relatively homogeneous laser intensity, through proper design and alignment of a qualifier mask, can limit each of these effects in the CDP. Misalignment of the qualifier mask relative to the axis of the laser beam or relative to the sizer DoF, will result in greater spatial heterogeneity in the CDP sizing response and greater droplet spectral broadening.

\subsubsection{Electronic response time}

Electronic response time can be an important limitation, both for counting all the droplets (Baumgardner et al., 1985) and for sizing them correctly (Baumgardner and Spowart, 1990). The CDP has very small deadtime losses, and uses a $40 \mathrm{MHz}$ clock. Faster electronics is one of the major improvements of the CDP over its predecessors.

\subsubsection{Coincidence}

Coincidence, which occurs when two or more droplets transit the sample area at the same time, is a concentration dependent problem that can cause undercounting and/or oversizing errors, and in general broadens the droplet size distribution. There are at least two types of coincidence in open path optical particle counting instruments, which have been previously discussed by Baumgardner et al. (1985), Cooper (1988) and Brenguier et al. (1989).

The first type of coincidence, which we call standard coincidence, occurs when two droplets pass through the qualified sample area, $\mathrm{SA}_{\mathrm{Q}}$, within rapid succession so that only one droplet is counted, and the size of the droplet appears to be 
larger than either of the single droplets alone because additional laser light is scattered into the sizing detector. For a Poisson probability distribution of droplet interarrival times, the probability of two droplets transiting through $\mathrm{SA}_{\mathrm{Q}}$ at the same time is $P=1-e^{-\lambda \tau}$ (Baumgardner et al., 1985), where $\lambda=N_{\mathrm{D}} \mathrm{SA}_{\mathrm{Q}}$ TAS, $N_{\mathrm{D}}$ is the droplet number concentration, TAS is the aircraft true air speed and $\tau$ is the amount of time that a droplet spends in the CDP laser beam (or the electronic pulse width). In the absence of coincidence errors or other counting errors, $\lambda$ is the droplet counting rate (droplets $\mathrm{s}^{-1}$ ). The probability of standard coincidence occurring in the CDP onboard the NOAA WP-3D aircraft is $<5 \%$ at $N_{\mathrm{D}}=500 \mathrm{~cm}^{-3}$, since the sensitive volume of the $\mathrm{CDP}$ laser beam is only $\sim 0.06 \mathrm{~mm}^{3}$ (given $\mathrm{SA}_{\mathrm{Q}} \sim 0.3 \mathrm{~mm}^{2}$, $\tau \sim 2 \mu$ s, and TAS $\sim 100 \mathrm{~m} \mathrm{~s}^{-1}$ ).

The second type of coincidence occurs when one droplet passes through $\mathrm{SA}_{\mathrm{Q}}$ and another droplet passes simultaneously just outside of $S A_{Q}$ but in an area where scattered light can still be detected by the sizer. We refer to this region, where non-qualified droplets can contribute scattered light to the sizer signal from qualified droplets, as the extended sample area, $\mathrm{SA}_{\mathrm{E}}$, and this type of coincidence as extended coincidence. When extended coincidence occurs, two things may happen: (1) the droplet passing through $\mathrm{SA}_{\mathrm{Q}}$ will be counted but will be oversized due to additional light scattered into the sizing detector from non-qualified droplets, or (2) the droplet passing through $\mathrm{SA}_{\mathrm{Q}}$ will not be counted because the additional light scattered from the coincident droplet will raise the sizer signal above the qualifier signal.

Coincidence errors in other cloud droplet instruments are typically considered minor for droplet concentrations $<500 \mathrm{~cm}^{-3}$ (Baumgardner et al., 1985). Cooper (1988), Brenguier et al. (1998) and Burnet and Brenguier (2002) present methodologies for correcting FSSP and Fast-FSSP measurements for coincidence errors. The most complicated of these correction schemes require measurement of interarrival times, pulse amplitudes and pulse widths for individual droplets, all of which are difficult to accurately measure when significant coincidence events occur.

\subsubsection{Counting statistics}

Statistical uncertainties result from the finite sample volume. With a $1 \mathrm{~Hz}$ sampling rate, on an aircraft such as the NOAA WP-3D flying at $100 \mathrm{~m} \mathrm{~s}^{-1}$, spatial variability within clouds cannot be resolved for spatial scales smaller than $100 \mathrm{~m}$. We determine the random statistical uncertainty in concentration using a Poisson probability distribution, based on the number of droplets measured in a sampling period and the sample volume. The uncertainty in droplet concentration due to counting statistics is less than 5\% for measured droplet concentrations $>13 \mathrm{~cm}^{-3}$ (given a $1 \mathrm{~Hz}$ sampling rate, aircraft velocity of $100 \mathrm{~m} \mathrm{~s}^{-1}$, and qualified sample area of $0.3 \mathrm{~mm}^{2}$ ).

\subsubsection{Particle shattering}

Particle shattering typically results in an instrument bias towards smaller and more droplets (Korolev et al., 2010). One potentially important advantage of the CDP compared to the FSSP is the use of two aerodynamic arms upstream of the open optical path, rather than the cylindrical inlet of the FSSP or CAS (which can be subject to large particle shattering artifacts Gardiner and Hallet, 1985; Heymsfield, 2007). McFarquhar et al. (2007) assert that the original CDP with rounded tips suffers much less from shattering artifacts than does the CAS. The pointed asymmetric tips on the CDP used during ARCPAC (Fig. 2b) are expected to further reduce ice shattering artifacts.

The interarrival time, or the time between observations of individual particles, gives a diagnostic of the extent of particle shatter on the particle size distribution, but significant uncertainty remains even after removing from the analysis those particles which are detected in groups of short interarrival times (Korolev et al., 2010). The CDP used during ARCPAC did not record particle interarrival times.

\subsubsection{Particle velocity}

During in-flight operation, uncertainty in the particle velocity as it crosses the laser path also translates directly and proportionally to uncertainty in the droplet concentration, because the velocity in part defines the sample volume. During ARCPAC, the cloud probes were suspended beneath (and slightly in front of) the outboard wing tip of the NOAA WP-3D to minimize effects from the wake of the aircraft. However, measurements made at three different points on the aircraft all show different values for true air speed (TAS), with a $-12 \mathrm{~m} \mathrm{~s}^{-1}$ and $-18 \mathrm{~m} \mathrm{~s}^{-1}$ bias in the readings of the CIP and CAS pitot tubes, respectively, compared to the aircraft TAS. The CIP pitot tube is closest in proximity to the CDP. To be conservative, we assume that the bias between TAS calculated from different sensors is due to measurement bias rather than real differences in airflow at the different locations. We use the aircraft TAS in calculations of droplet concentration, both because we expect it to be the most accurate measurement and because the small pitot tubes located in close proximity to the probes, although heated, often became blocked with ice during flights in the Arctic. Since the aircraft TAS is the highest of the three TAS readings, we report the lowest expected droplet concentrations. Therefore, we assume an uncertainty in TAS of $18 \mathrm{~m} \mathrm{~s}^{-1}$, which results in an uncertainty in droplet concentrations of $\sim 20 \%$ for the ambient measurements. The average TAS for the NOAA WP-3D was $\sim 125 \mathrm{~m} \mathrm{~s}^{-1}$ during ARCPAC. 


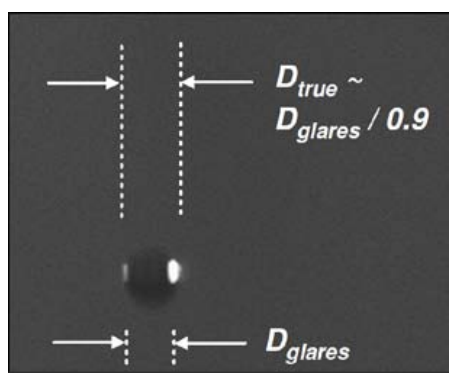

(a)

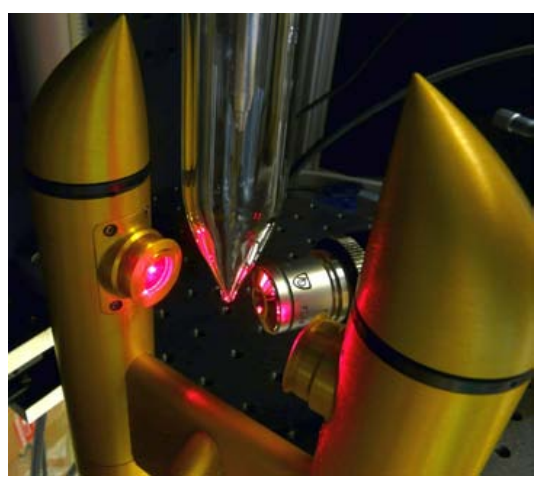

(b)

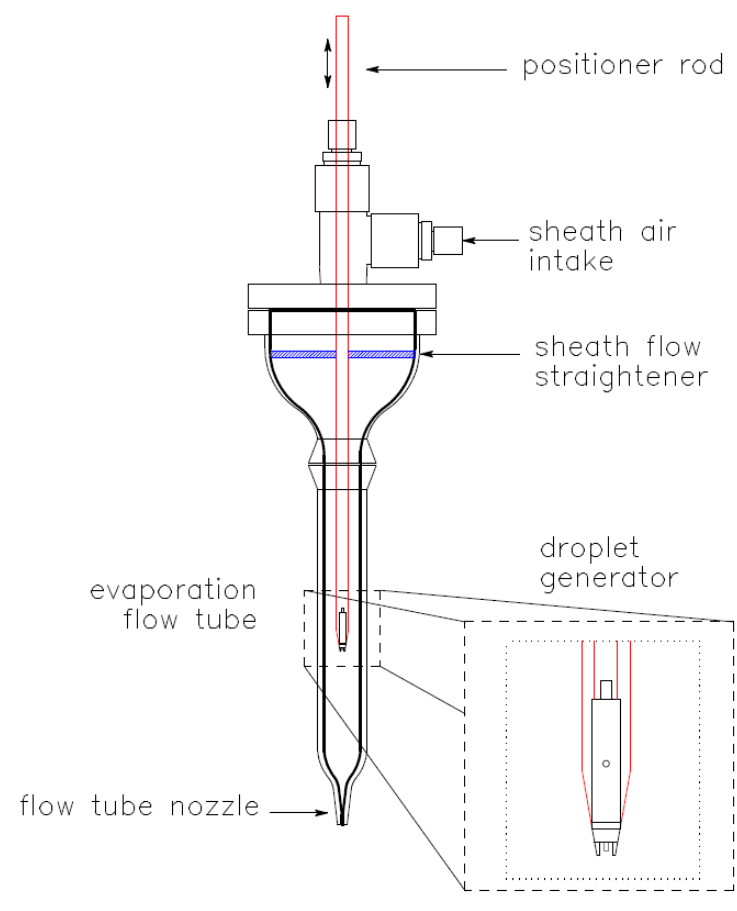

(c)

Fig. 2. (a) Photograph of a single droplet in the sample area of the CDP, seen at an angle of $121^{\circ}$ from incident, using a shutter speed of $1 / 300000 \mathrm{~s}^{-1}$, (b) Photograph of the evaporation flow-tube positioned above the sample area of the CDP during calibration with water droplets, and (c) diagram of the glass evaporation flow-tube used for the water droplet calibrations of the CDP.

\section{Methods}

\subsection{Calibration system}

A calibration system was developed to quantify uncertainties relating to the CDP sample area, sizing resolution, coincidence errors and electronic response time using monodisperse water droplets $8-35 \mu \mathrm{m}$ in diameter. Table 2 lists the main components of the calibration system, with many similarities to the systems used by Wendisch et al. (1996) and Nagel et al. (2007). Lee (2003) provides a comprehensive description of droplet generation methods.

Droplets are generated using a commercial piezo-electric drop generator. Stable operation of the generator (production of a single, straight jet of uniform droplets, without production of smaller satellite drops), requires specific operating parameters, which are fluid and orifice dependent. For generation of water droplets using a $30 \mu \mathrm{m}$ nozzle, the most stable operation is maintained with the following parameters: $3 \mu$ sise, $22 \mu$ s dwell, $3 \mu$ s fall, $44 \mu$ s echo, $3 \mu$ s final rise, 0 volts idle, 16 volts dwell and -16 volts echo at $250 \mathrm{~Hz}$ $\left(n_{\mathrm{D}}=250\right.$ droplets s$\left.^{-1}\right)$. These parameters produce $\sim 40 \mu \mathrm{m}$ droplets. A $2 \mu \mathrm{m}$ nylon filter is used in the liquid flow upstream of the droplet dispensing device. Care must be taken to eliminate bubbles from the water supply to the device. The droplet generation system uses a liquid pump and a manifold of valves to allow transitioning between three different modes of operation without allowing bubbles into the system. These three modes of operation are: (1) purging the drop generator device using a liquid pump with a positive pressure head, (2) drawing in a cleansing solution via a negative pressure head, and (3) operating the drop generator device under static pressure in equilibrium with a water reservoir, bypassing the liquid pump altogether (normal operation). Periodic wetting and purging of the device eliminates bubbles and also prevents accumulation of electric charge on the outer surface of the glass nozzle, which can alter the droplet trajectories and prevent droplet generation. It was discovered that droplet generation is not as sensitive to the water reservoir pressure head as expected from previous studies (e.g. Wendisch et al., 1996) as long as the level of the water reservoir is below the tip of the drop generation device, resulting in a slight negative pressure and a concave meniscus. Vertical operation is also important, as a symmetrical meniscus in the droplet dispensing device nozzle prevents the droplet jet from ejecting at an angle, or from not being generated at all. Thus, the CDP is oriented vertically during the calibrations. The performance of the drop generator device is monitored with 
Table 2. Essential Components of the Water Droplet Calibration System.

\begin{tabular}{|c|c|c|c|}
\hline Component Description & Manufacturer/Supplier & Model \#/ Part \# & Specifications \\
\hline $\begin{array}{l}\text { Metrology camera } \\
\text { w/ high speed shutter }\end{array}$ & JAI & CV-A10 CL & $\begin{array}{l}0.5^{\prime \prime} \mathrm{CCD} \\
1 / 60-1 / 300000 \mathrm{~s}^{-1} \\
\text { shutter speeds } \\
0.44 \text { MPixel resolution } \\
(575 \times 760 \text { pixels })\end{array}$ \\
\hline Diagnostic camera & $\begin{array}{l}\text { BigCatch USB } \\
\text { digital cameras }\end{array}$ & EM-310C & $0.5^{\prime \prime} \mathrm{CMOS}$ \\
\hline $\begin{array}{l}\text { Microscope objectives } \\
\text { and lens tubes }\end{array}$ & Edmund Optics & - & $\begin{array}{l}4 \times, 10 \times \text { and } 20 \times \\
\text { magnifications }\end{array}$ \\
\hline $\begin{array}{l}\text { Drop generator device/ } \\
\text { Piezo-electric actuator }\end{array}$ & MicroFab, Inc. & $\begin{array}{l}\text { MJ-ABP-30/ } \\
\text { JetDrive III }\end{array}$ & $\begin{array}{l}30 \mu \mathrm{m} \text { orifice/ } \\
\text { Strobe control }\end{array}$ \\
\hline Evaporation flow-tube & $\begin{array}{l}\text { Allen Scientific } \\
\text { Glass }\end{array}$ & - & $\begin{array}{l}28 \mathrm{~cm} \text { long evaporation } \\
\text { section, ID }=2 \mathrm{~cm}, \\
\text { tapering to nozzle with } \\
\text { ID }=0.5 \mathrm{~mm}\end{array}$ \\
\hline Oscilloscope & Tektronix & THS720A & 2 channel $100 \mathrm{MHz}$ \\
\hline Water pump & McMaster-Carr & $8220 \mathrm{~K} 43$ & low flow gear pump \\
\hline Water manifold & Cole-Parmer & A-06464-85 & (4) 3-way valves \\
\hline Image acquisition card & National Instruments & PCIe-1427 & - \\
\hline
\end{tabular}

a diagnostic camera at $4 \times$ magnification and an LED strobe light synchronized to the piezo-electric actuator signal with a variable delay control, similar to Schafer et al. (2007).

Generated droplets then pass through an evaporation flowtube (Fig. 2c) to accelerate the drops to greater speeds and to make fine adjustments to the droplet size by controlled evaporation. The droplets are injected into a laminar, dry sheath air flow. The residence time between the point of injection and the exit of the flow-tube controls the extent of droplet evaporation. The residence time can be controlled by changing either the sheath flow rate or the injection position of droplets inside the flow-tube. The speed of the droplets exiting the flow-tube is sensitive to both the flow rate and the droplet size; large droplets require a finite travel distance for acceleration, which is a function of the particle relaxation time. By varying the injection position within the flow-tube and the flow rate, it is possible to explore two different effects (droplet size and speed) on the sizing and counting efficiency of the CDP. Water and piezo-electric actuator pulses are supplied within the injection positioning rod. A residence time of several seconds is required to evaporate droplets from $40 \mu \mathrm{m}$ to less than $10 \mu \mathrm{m}$, depending on the relative humidity (RH) in the flow-tube. Neither the RH nor the residence time of droplets in the flow-tube is monitored; instead the droplet size is determined with an independent measurement, as explained below. The droplets accelerate to velocities up to
$45 \mathrm{~m} \mathrm{~s}^{-1}$ in the tapered section of the flow-tubein the tapered nozzle of the evaporation flow-tube. Figure $2 \mathrm{~b}$ shows a photograph of the evaporation flow-tube during calibration of the CDP. The exit of the flow-tube nozzle is positioned $<5 \mathrm{~mm}$ above the CDP sample area.

For all calibrations of the CDP, the standard CDP binned size distributions are recorded in addition to the waveforms of individual electronic pulses (obtained using an oscilloscope configured to sample the sizer and qualifier signals for a subset of all detected particles). The amplitude of electronic pulses recorded by the sizer (which we refer to as the "sizer pulse amplitude") corresponds to the maximum scattered light intensity detected by the sizer as a particle transits across the CDP laser beam. The "qualifier pulse amplitude" is similarly defined.

For independent verification of the droplet diameter, we utilize the "glares technique" described in previous papers (Korolev et al., 1991; Wendisch et al., 1996; Nagel et al., 2007), in which a camera directly images droplets as they pass through the laser beam of the CDP. The geometry of specular reflections off the front and back face of droplets, as observed by a camera situated at a given angle from the incident light, uniquely constrains the droplet size. Figure $2 \mathrm{a}$ shows a single droplet illuminated by the CDP laser beam, with two bright "glares" produced at the edge of the droplet image. Although the image is vertically blurred slightly due 
to the droplet motion, the shape of the droplet is apparent by way of independent backlighting (used for acquisition of this image only). Linear glares are produced when the droplet transits across a passive camera, allowing the glares to streak across the acquired image (e.g. Nagel et al., 2007). The distance between the centerlines of the two glare streaks is $D_{\text {glares }}$. At a viewing angle of $120-130^{\circ}, D_{\text {glares }}$ is least sensitive to viewing angle and the true droplet diameter, $D_{\text {true }}$, is $\sim 10 \%$ greater than $D_{\text {glares }}$ (Wendisch et al., 1996). At a viewing angle of $125^{\circ}$, a change of $\pm 10^{\circ}$ results in a change of $<1 \%$ for $D_{\text {glares }} / D_{\text {true }}$. The uncertainty in viewing angle is actually much less than $10^{\circ}$ for our calibrations. Since the light source for the glares measurement is the CDP laser, this technique allows for verification of the droplet size within the sample area of the CDP, simultaneous to, but not affecting, the standard CDP measurement. For measuring $D_{\text {glares }}$, we use a digital metrology camera at $20 \times$ magnification focused on droplets as they transit the sample area of the CDP, with a viewing angle of $121^{\circ}$ to the incident light. The positioning of the droplets is highly repeatable as verified by observing that droplets remain in-focus and consistently positioned in the acquired image during the calibration experiments. The sizing of the metrology camera is independently calibrated both with backlit glass beads adhered to a transparent slide and with a standard optical test target. The uncertainty in the droplet sizing is dominated by the pixel resolution of the metrology camera setup, which is $0.54 \mu \mathrm{m} /$ pixel. For droplets with diameter $>8 \mu \mathrm{m}$, the sizing uncertainty for this method is $<14 \%$. Uncertainty in droplet positioning is $<20 \mu \mathrm{m}$.

The droplet velocity is estimated by measuring the length of the droplet glares (parallel to the droplet trajectory and perpendicular to $D_{\text {glares }}$ ) while varying the amount of time the shutter of the metrology camera is held open. The slope of this relationship provides the droplet velocity. The maximum droplet velocity measurable is dependent on many factors including the optical magnification, the field of view, the pixel size resolution, the amount of light scattered and collected, the width of the laser beam, and the maximum shutter speeds available. $10 \times$ magnification was found to produce the optimum conditions for measuring the velocity of 10 $20 \mu \mathrm{m}$ droplets, which allows for a maximum droplet velocity measurement of $\sim 70 \mathrm{~m} \mathrm{~s}^{-1}$ across the CDP laser beam. For smaller droplets, the maximum measureable droplet velocity is lower, due to the dimness of the glares. Droplet velocity may be important for two different reasons: (1) the electronic response time of the CDP may truncate the pulses when droplets pass at a faster velocity (Baumgardner and Spowart, 1990; Nagel et al., 2007), and (2) the droplet trajectories may be influenced by the laser beam itself when passing at a slower velocity (Nagel et al., 2007). These effects could influence the measured pulse width and height in addition to the counting rate. The evaporation flow-tube and sheath flow rate used in these calibrations resulted in droplet velocities of $30-40 \mathrm{~m} \mathrm{~s}^{-1}$ for droplets smaller than $25 \mu \mathrm{m}$.

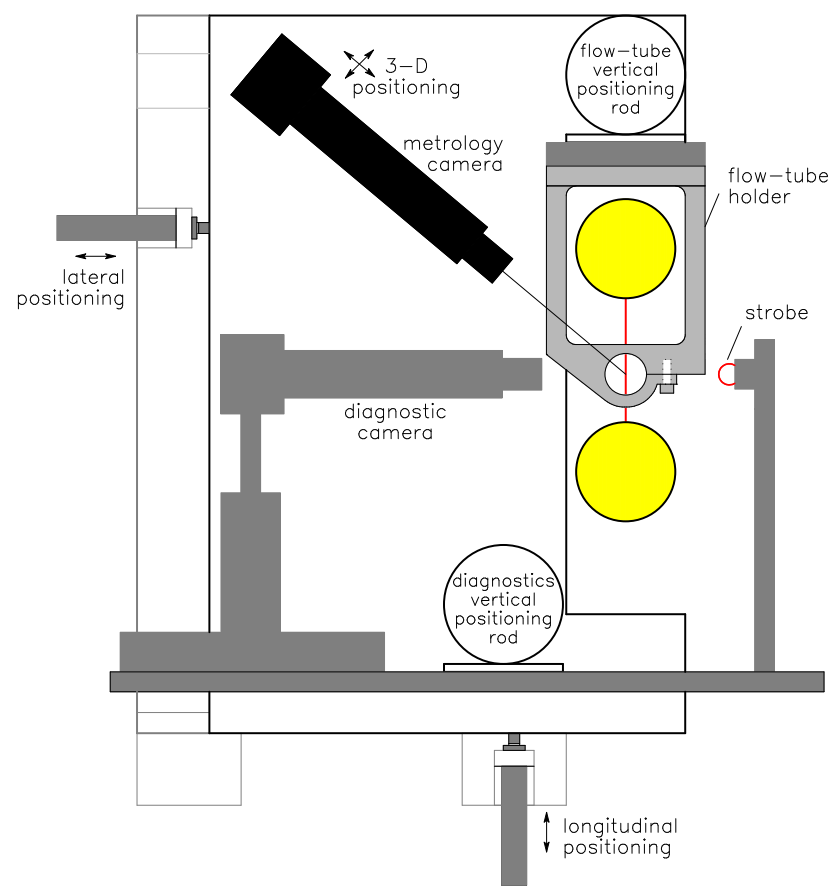

Fig. 3. Schematic of the calibration system, as viewed from above, illustrating the lateral and longitudinal directions. Yellow circles indicate the two arms of the CDP and the red line indicates the CDP laser beam.

While these velocities are significantly lower than the aircraft velocity, they are high enough to prevent problem \#2 above. Future work is planned using a flow-tube with a much longer flow-tube nozzle $(\sim 4 \mathrm{~cm})$, to allow greater time for droplet acceleration prior to exit, so that we may more thoroughly explore the effect of droplet velocity on the CDP response.

The calibration system allows for precisely controlling the horizontal positioning of droplets during calibration, so that we can experimentally evaluate the degree to which random positioning of droplets within $\mathrm{SA}_{\mathrm{Q}}$ (longitudinally along the axis of the laser beam and laterally across the laser beam) will broaden droplet size distributions measured in flight. This is accomplished by mounting the entire optical setup on a large two dimensional translation stage surrounding the CDP (Fig. 3). Precise positioning of the droplets in the CDP laser beam also allows for measurement of the qualified sample area, $\mathrm{SA}_{\mathrm{Q}}$, and the extended sample area, $\mathrm{SA}_{\mathrm{E}}$, both of which are required for quantifying coincidence errors in the CDP.

\subsection{Monte carlo simulations}

To simulate the effect of coincidence errors on the CDP performance, we developed a Monte Carlo program with two independent time scales, one for qualified droplets transiting 
through $\mathrm{SA}_{\mathrm{Q}}$ and one for nonqualified droplets transiting through $\mathrm{SA}_{\mathrm{E}}$. In the simulations, first an input droplet size distribution is prescribed, and individual droplets within this distribution transit the CDP laser at random time intervals and positions. A Poisson probability distribution of droplet interarrival times $(\Delta t)$ is assumed both for qualified and nonqualified droplets (Field et al., 2003),

$\frac{d P(\Delta t)}{d t}=\left(\frac{1}{\tau}\right) \exp \left(\frac{-\Delta t}{\tau}\right)$

$\tau_{\mathrm{Q}}=\frac{1}{n_{\mathrm{D}}}$

$\tau_{\mathrm{C}}=\frac{1}{n_{\mathrm{D}}}\left(\frac{\mathrm{SA}_{\mathrm{Q}}}{\mathrm{SA}_{\mathrm{E}}}\right)$

where $\tau_{\mathrm{Q}}$ is the average time between qualified droplets, $\tau_{\mathrm{C}}$ is the average time between nonqualified droplets (which have the potential to act as coincident droplets), and $n_{\mathrm{D}}$ is the prescribed qualified droplet counting rate (droplets $\mathrm{s}^{-1}$ ). In these simulations, transit of droplets across any position within $\mathrm{SA}_{\mathrm{Q}}$ and $\mathrm{SA}_{\mathrm{E}}$ is considered equally likely.

Nonqualified droplets can influence the scattering signal from qualified droplets even when the two droplets do not arrive at exactly the same time. This is because, in addition to the interarrival time between droplets, coincidence errors depend on the finite time that droplets spend transiting the laser beam, which can be characterized by the electronic pulse width. At $100 \mathrm{~m} \mathrm{~s}^{-1}$ flight speed, droplets will pass through a $0.2 \mathrm{~mm}$ diameter laser beam in $2 \mu \mathrm{s}$. If the droplet interarrival time is $<2 \mu \mathrm{s}$, then the scattering signals from the two droplets will overlap, and we consider this to be a coincidence event. At higher velocities, the electronic pulse width and the average interarrival time will decrease by an equal proportion. This is important to understand, because it means that the aircraft velocity does not directly affect the coincidence error.

All else being equal, wider pulses result in greater overlap between pulses, and greater coincidence errors. Pulse widths for individual droplets are not measured during standard operation of the CDP, and depend on multiple factors including the width of the laser beam at a given location, the droplet size, and the aircraft velocity. Measured pulse widths during the water droplet calibrations ranged from 2$7 \mu \mathrm{s}$, for droplets $8-35 \mu \mathrm{m}$ in diameter traveling at roughly $25-35 \%$ of the NOAA WP-3D velocity through the center of the qualifier DoF. Therefore, we expect a range of pulse widths roughly $0.5-2.5 \mu$ s during the ARCPAC campaign.

Since the pulse widths during in-flight sampling are not known precisely, we use the measured average transit time to constrain the pulse widths used in the simulations. In the $\mathrm{CDP}$, the average transit time of qualified droplets is operationally defined as the duration for which the simulated sizer signal exceeds a threshold of 20 digital counts until the sizer signal drops below 10 digital counts (as long as the qualifier signal exceeds the sizer signal at some point during this time period). For a series of coincident droplets, the measured transit time configured in this way can be very long; the average transit time can therefore be used as a diagnostic for in-flight coincidence errors. We use a time window of $100 \mu \mathrm{s}$ in the simulations to allow for long transit times, so that this diagnostic parameter can be evaluated.

Droplet size also has an important effect on coincidence errors. Doubling the amount of light reaching the sizer (the maximum effect possible due to extended coincidence since the maximum qualifier/sizer signal ratio is $\sim 2$ ) has a greater effect on the measured droplet size when the droplets are small. As an example, doubling the voltage from 195 to $390 \mathrm{mV}$ represents an increase in droplet diameter from 6.4 to $13.2 \mu \mathrm{m}$ (a $106 \%$ increase), whereas doubling the voltage from 372 to $744 \mathrm{mV}$ represents an increase in droplet diameter from 12.6 to $21.2 \mu \mathrm{m}$ (a $68 \%$ increase). This means that a monodisperse distribution of $6.4 \mu \mathrm{m}$ droplets can have up to $38 \%$ greater oversizing error due to coincidence than a monodisperse distribution of $12.6 \mu \mathrm{m}$ droplets. In terms of the relative increase in LWC, the size difference has a much greater effect.

The simulations are constrained by the measured response of the sizer and qualifier to individual water droplets within $\mathrm{SA}_{\mathrm{Q}}$ and $\mathrm{SA}_{\mathrm{E}}$. An individual droplet is allowed to transit randomly across $\mathrm{SA}_{\mathrm{Q}}$, and the pulse amplitude is then modified according to the instrument response at that given position within $\mathrm{SA}_{\mathrm{Q}}$. Simultaneously, other droplets may randomly transit across $S A_{E}$, whereby simulated pulses are generated with amplitudes that depend on their position within $\mathrm{SA}_{\mathrm{E}}$. Thus, the simulations not only account for coincidence errors, but also account for the spatially heterogeneous sizing response within $\mathrm{SA}_{\mathrm{Q}}$ (introduced in Sect. 2.5.2). The qualifier and sizer signals for all droplets transiting across $\mathrm{SA}_{\mathrm{E}}$ and $\mathrm{SA}_{\mathrm{Q}}$ within a $\pm 50 \mu$ s time window relative to the prescribed qualified droplet are then summed (note that multiple qualified droplets are possible in the simulations, which means that there is the possibility of standard coincidence, but nonqualified droplets are far more likely since $\mathrm{SA}_{\mathrm{E}} \gg \mathrm{SA}_{\mathrm{Q}}$ ). We assume in the simulations that the scattered light from one droplet does not affect the scattering response of any other droplet.

The Monte Carlo simulations are each run with a sampling of 500 qualified droplets for prescribed droplet concentrations ranging from 10 to $510 \mathrm{~cm}^{-3}$ and four prescribed droplet size distributions (normal distributions with volume mean diameter, $D_{V}=5,7.5,10$ and $20 \mu \mathrm{m}$, respectively, and standard deviation of $\pm 0.05 D_{V}$ ). The instrument response is simulated by binning the resulting sizer signals according to the standard CDP diameter bins, which are then shifted by $2 \mu \mathrm{m}$ as described in Sect. 4.1.1. 


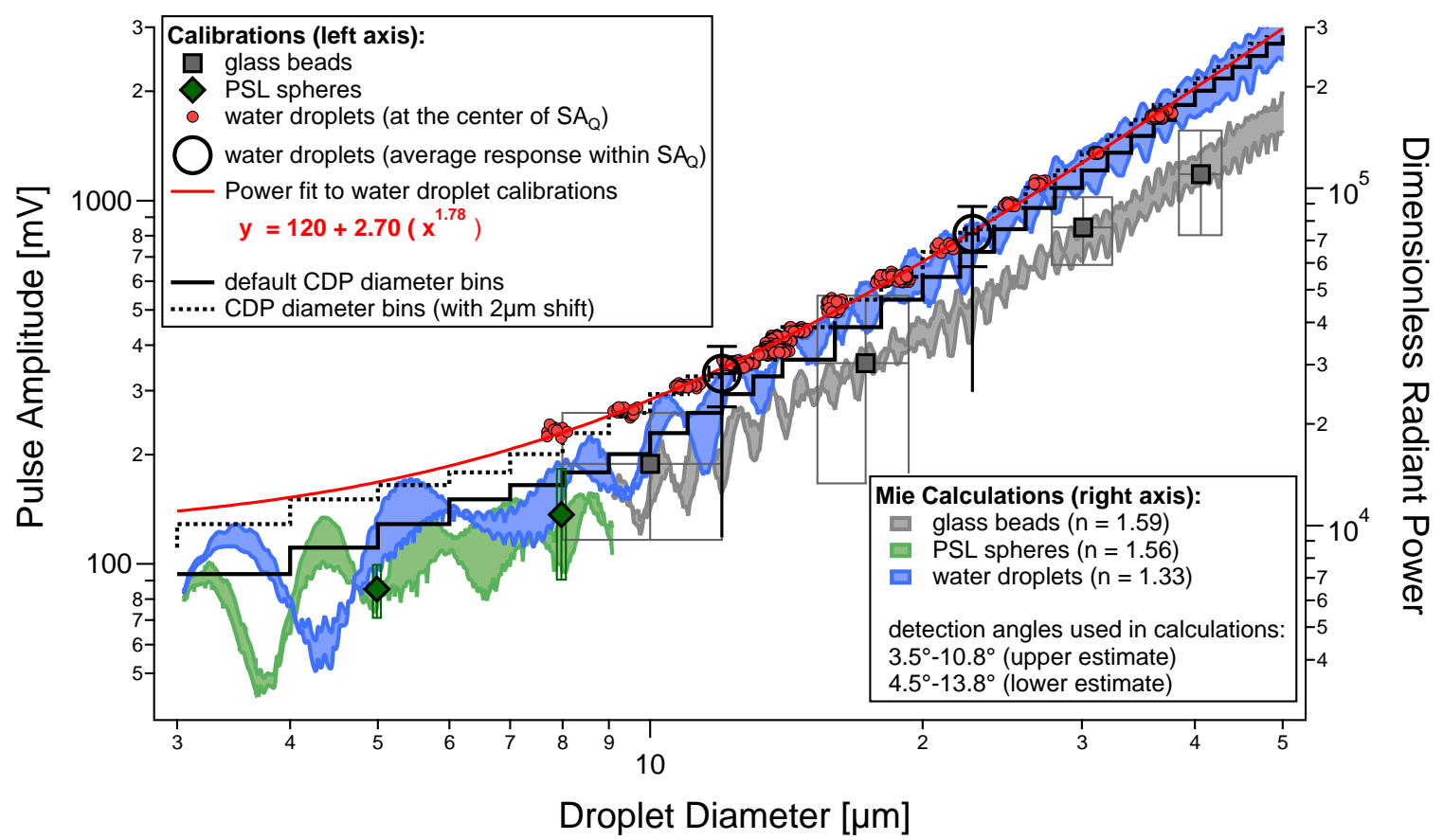

Fig. 4. CDP sizer pulse amplitude (in milliVolts, on the left axis) versus the "true" droplet diameter (obtained from images of the droplet glares) within the sample area of the CDP for calibrations using glass beads, polystyrene latex (PSL) spheres and water droplets. Also plotted are the calculated response functions of the CDP (dimensionless radiant power collected, on the right axis) as a function of droplet diameter, calculated using a given range of collection angles and refractive indices. The scales of the two axes are adjusted to obtain alignment between the calibrations and the theoretical curves. Uncertainties in the glass bead and PSL particle sizes represent one standard deviation as provided by Fischer Scientific, Inc. Uncertainties in the pulse amplitude are one standard deviation of the observed pulse amplitudes.

\subsection{Phase discrimination and definition of a cloud}

Phase discrimination is performed for every $1 \mathrm{~s}$ sampling interval during the ARCPAC flights. The following criteria are used to identify mixed-phase clouds (for liquid-only clouds, only the first and third criteria are met):

- $10 \mathrm{~cm}^{-3}$ particles with diameter $<50 \mu \mathrm{m}$ (as measured by the CDP)

- $0.01-0.02 \mathrm{~L}^{-1}$ particles with diameter $>400 \mu \mathrm{m}$ (as measured by the PIP)

- $0.1 \mathrm{gm}^{-3}$ LWC (as measured by the King-LWC probe)

The first criterion is essentially the same as that used by Hobbs and Rangno (1998) for mixed-phase clouds, whereas the second criterion is modified to reflect new information that has been discovered about ice shattering artifacts. Ice particles with diameter $>\sim 400 \mu \mathrm{m}$ are much less susceptible to shattering artifacts (Korolev et al., 2010) than the $100 \mu \mathrm{m}$ size cut used by Hobbs and Rangno (1998). Furthermore, phase identification based on CIP and PIP images is much more reliable when the particle diameter is $>400 \mu \mathrm{m}$. However, ice concentrations at $400 \mu \mathrm{m}$ are typically $\sim 2$ orders of magnitude lower than concentrations at $100 \mu \mathrm{m}$. We therefore use a threshold concentration for the second criterion that is two orders of magnitude lower than that used by Hobbs and Rangno (1998). Because this lower concentration cutoff approaches the counting limits of the PIP, our second criterion is chosen to limit concentration uncertainty due to counting statistics to $<50 \%$ for particles $>400 \mu \mathrm{m}$. The range of concentrations for this second criterion is a result of the fact that the sample area for PIP measurements, and therefore the concentration uncertainty, is dependent on the particle size.

When the first two criteria are met, but the third criterion is not, we refer to the cloud as an "ice or mixed-phase cloud". Under these conditions we cannot state with confidence whether the particles observed by the CDP are ice or liquid, since ice can apparently bias the King-LWC measurements by as much as $0.08 \mathrm{~g} \mathrm{~m}^{-3}$. To limit relative uncertainties caused by icing or impaction of ice on the KingLWC probe, we also use this third criterion when reporting the CDP-LWC bias, defined as:

CDP-LWC bias $=100 \%\left(\frac{\text { CDP-LWC }- \text { King-LWC }}{\text { King-LWC }}\right)$

The third criterion limits the CDP-LWC bias to values $>-80 \%$ (assuming that the King-LWC can be biased by as much as $0.08 \mathrm{~g} \mathrm{~m}^{-3}$ and assuming no errors in the CDP-LWC). 


\section{Results}

\subsection{Laboratory characterization of the CDP}

\subsubsection{CDP sizing response}

The CDP was calibrated with PSL spheres, glass beads and water droplets. The sizer pulse amplitudes for these calibrations are plotted on the left axis of Fig. 4. Plotted on the right axis are the theoretically determined response functions of the CDP for different particle refractive indices, calculated from Mie theory. The range of collection angles for the theoretical curves illustrates the expected sensitivity of the CDP response to changes in the droplet position within the qualified sample area.

Glass beads were aspirated from a small vial and through a tube positioned over the sample area of the CDP using dry compressed gas. The PSL calibrations were performed using a nebulizer followed by a diffusional dryer to evaporate the water from the PSL particles. The PSL particles were then transmitted across the sample area of the CDP using the evaporation flow-tube. For both the PSL and glass bead calibrations aggregation of generated particles is possible, which would result in a bias in the measured pulse amplitude. Coincidence is also possible, but is extremely unlikely for the PSL calibrations, since particle count rates were less than $0.1 \mathrm{~Hz}$. By manually adjusting the scales of the left and right axes in Fig. 4 to align the glass bead and PSL calibrations with their respective theoretical response curves, the theoretical response curve for water droplets becomes aligned with the default CDP bin designations. This suggests that the instrument is performing the same as when it was calibrated by the manufacturer.

Monodisperse water droplets $8-35 \mu \mathrm{m}$ in diameter were generated for calibration of the CDP. Droplets were injected through the CDP laser beam at the lateral and longitudinal position that produced the maximum qualifier pulse amplitude. Once this position was located, which corresponds to the center of the qualifier DoF, calibration with various droplet sizes commenced. Figure 4 shows the sizer response to water droplets; no averaging was performed and each data point represents a single droplet at the center of the qualifier DoF as measured with the metrology camera and with the oscilloscope. These calibrations are fit using a power law relationship. The response of the CDP as a function of droplet size is surprisingly monotonic, which is unexpected based on the Mie calculations, for reasons that are not readily apparent.

The CDP also appears to oversize droplets, especially for droplet sizes smaller than $20 \mu \mathrm{m}$, when using the glass bead and PSL particles for calibration. By shifting the bin designations by $2 \mu \mathrm{m}$, the CDP response more accurately represents the true droplet diameter obtained from images of the droplet glares. Figure 5 shows the volume mean diameter ( $D_{V}$, Seinfeld and Pandis, 1998) calculated from the droplet

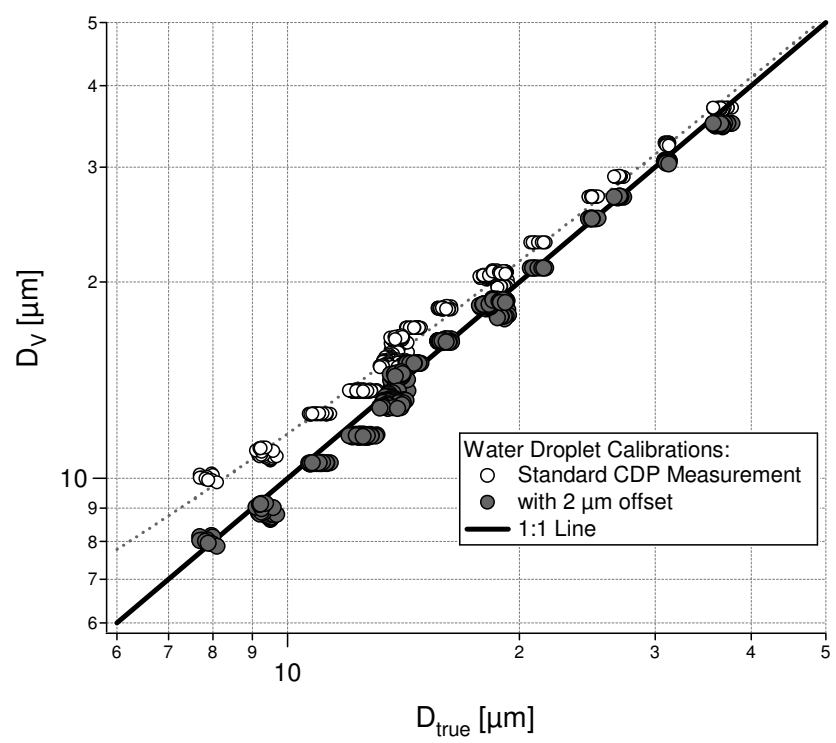

Fig. 5. Volume mean diameter $\left(D_{V}\right)$ from the standard CDP measurement versus $D_{\text {true }}$ determined from images of the droplet glares.

size distributions reported in the standard CDP measurement (with the threshold diameter in the CDP software representing the smallest diameter of each bin) as a function of the true droplet diameter obtained from images of the droplet glares. Droplets are systematically oversized by up to $20 \%$ using the standard CDP diameter thresholds. Subtracting $2 \mu \mathrm{m}$ from each size bin produces much better agreement, with a slope of $0.977 \pm 0.0013$ (forced through the origin) and a linear correlation coefficient $\left(R^{2}\right)$ of 0.994 . Droplets may still be under or over sized by as much as $10 \%$, even when the droplets transit directly through the center of the qualifier DoF, due to the coarse size resolution of the size bins.

Figure 6a and $\mathrm{d}$ show the CDP droplet sizing accuracy $\left(D_{V} / D_{\text {true }}\right)$ as a function of position within the $\mathrm{SA}$ for two different droplet sizes ( $22 \mu \mathrm{m}$ and $12 \mu \mathrm{m})$, after the $2 \mu \mathrm{m}$ sizing offset has been applied. The measurements were obtained at regular intervals of $200 \mu \mathrm{m}$ along the axis of the laser beam and $20 \mu \mathrm{m}$ across the laser beam, with higher resolution at the edges of the qualified sample area (to within $50 \mu \mathrm{m}$ and $10 \mu \mathrm{m}$, respectively) after the edge has been identified through the absence of counts on the CDP. The variability of droplet sizing accuracy within $\mathrm{SA}_{\mathrm{Q}}$ is large, with undersizing by as much as $74 \%$ possible as well as oversizing by as much as $12 \%$, but only a small fraction of the area within $\mathrm{SA}_{\mathrm{Q}}$ results in undersizing by more than $25 \%$. These calibrations show that the sizer response is not symmetric with the center of the qualifier DoF, which suggests that there is a slight misalignment between the qualifier DoF and the sizer DoF. This is likely because the qualifier mask is not aligned perfectly with the center of the sizing detector. 

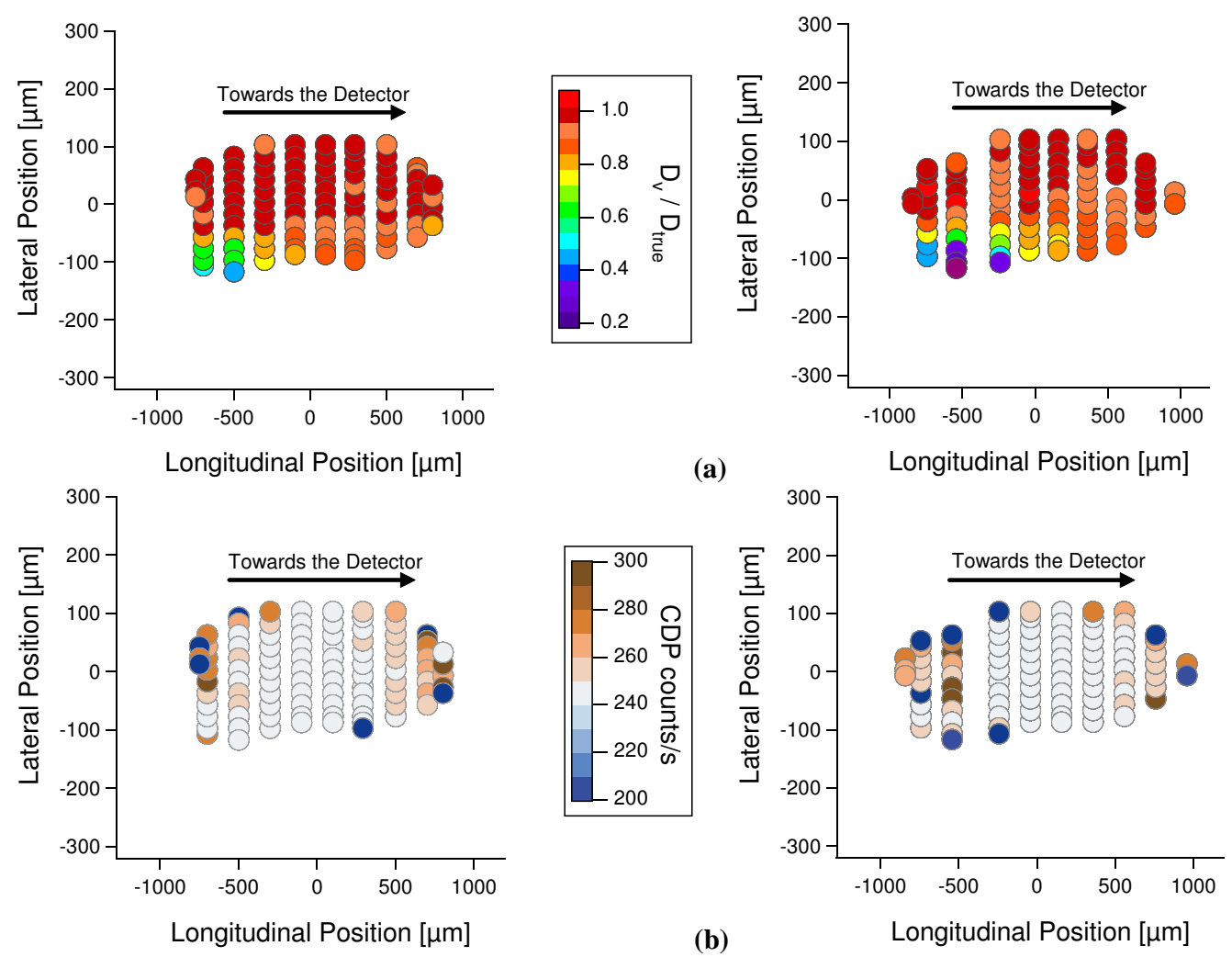

(a)
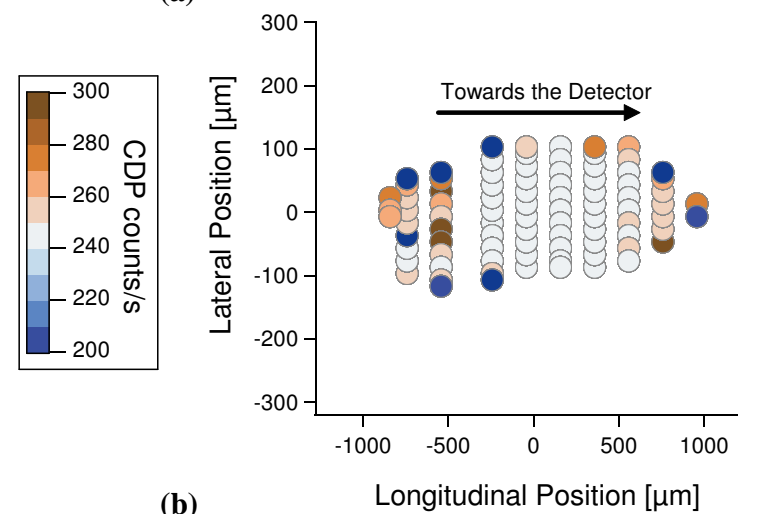

(d)

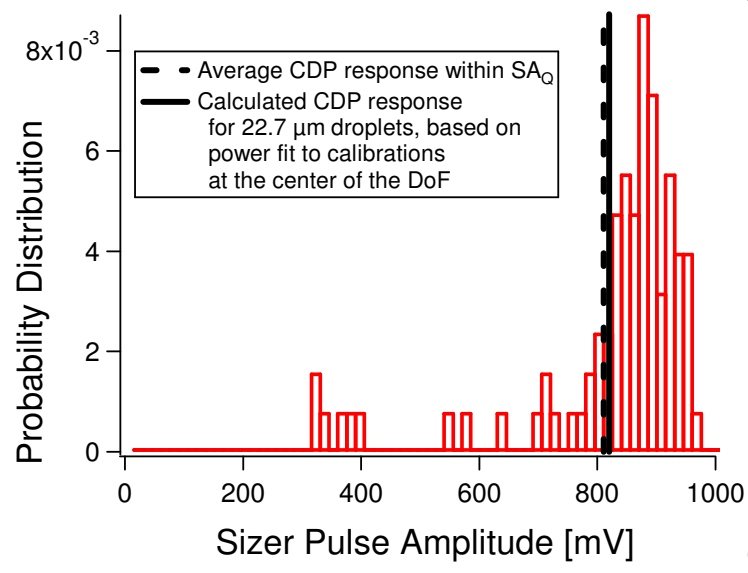

(b)

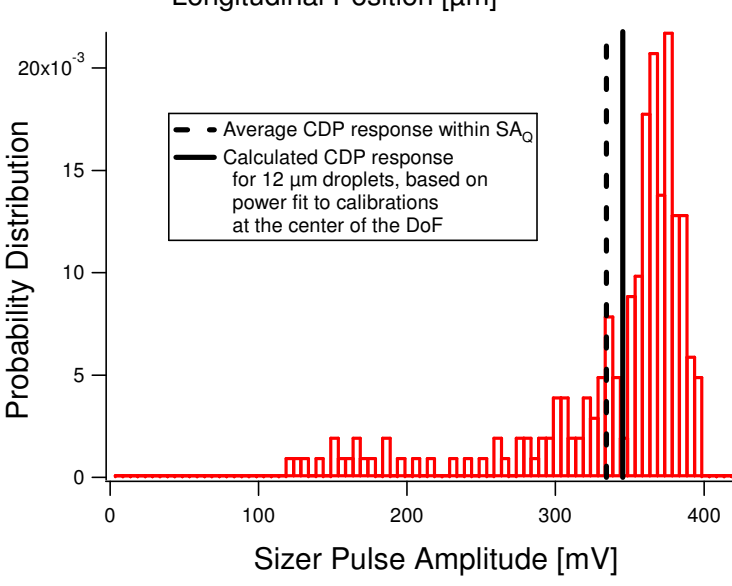

(e)

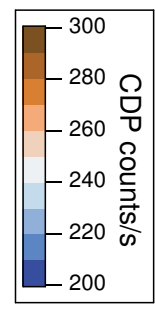

(c)

Sizer Pulse Amplitude [mV]

(f)

Fig. 6. Calibrated CDP sizing and counting response as a function of lateral and longitudinal position using $22 \mu \mathrm{m}(\mathbf{a}$ and $\mathbf{b})$ and $12 \mu \mathrm{m}(\mathbf{d}$ and e) water drops, at $35-40 \mathrm{~m} \mathrm{~s}^{-1}$ velocity. (c) and (f) show histograms of the sizer pulse amplitude within $\mathrm{SA}_{\mathrm{Q}}$.

The measured sizer pulse amplitude is also analyzed for these calibrations where droplet position is varied within $\mathrm{SA}_{\mathrm{Q}}$. Included in Fig. 4 are the average, standard deviation, maximum and minimum sizing response within $\mathrm{SA}_{\mathrm{Q}}$ for 22 and $12 \mu \mathrm{m}$ water droplets. The pulse amplitude averaged over all positions within $\mathrm{SA}_{\mathrm{Q}}$ for these two droplet sizes agrees well with the power fit to the droplet sizing calibrations where droplets transit only across the center of the qualifier DoF. This shows that the power fit adequately describes the average response of the instrument to droplets randomly intercepted within $\mathrm{SA}_{\mathrm{Q}}$. Figure $6 \mathrm{c}$ and $\mathrm{f}$ show histograms of the sizer pulse amplitude within $\mathrm{SA}_{\mathrm{Q}}$. These histograms are used in the Monte Carlo simulations to characterize the measurement broadening of an actual droplet size distribution, and can be used to calculate the "distortion matrix" used by Wendisch et al. (1996).

Both the lack of Mie resonance structure and the greater than expected sizing response for water droplets at one position within $\mathrm{SA}_{\mathrm{Q}}$ suggest that the optical model used to extrapolate from the PSL and glass beads calibrations is inappropriate for this particular instrument. Knollenberg (1976) suspected that Mie resonance structure could be dampened with the use of a multi-mode laser, and Korolev (1985) used this idea to explain the lack of observed resonance for their 


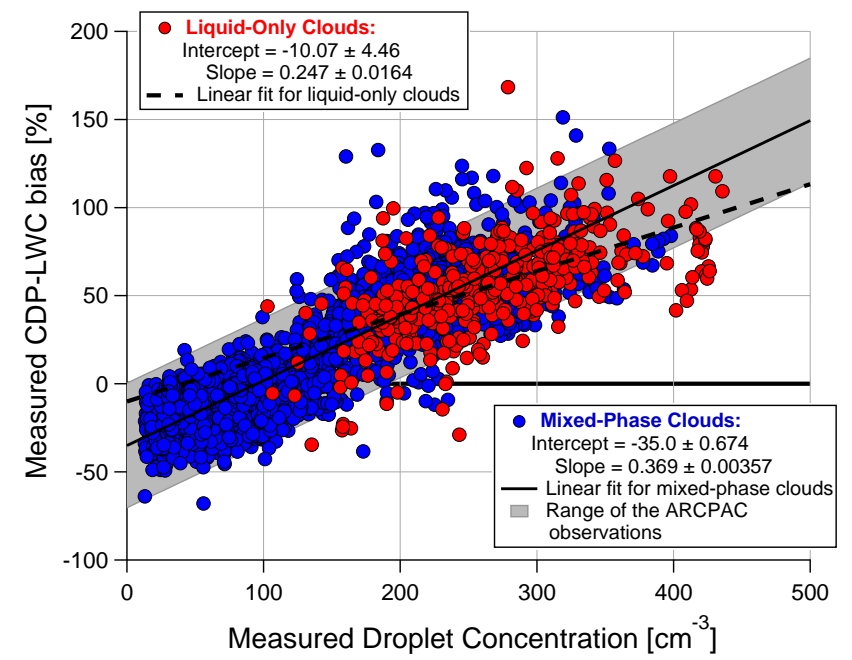

Fig. 7. CDP-LWC bias (Eq. 4) for 1Hz measurements in liquid-only clouds on transit flight from Tampa to Denver on 29 March 2008 and in mixed-phase clouds on six ARCPAC flights $(11,12,15,18$, 19 and 21 April 2008). Grey shaded region shows one standard deviation of the mixed-phase cloud observations.

FSSP when calibrated with water droplets. However, Pinnick et al. (1982) stated that "... the theoretical response calculations adequately predict the FSSP response for spheres, regardless of effects that may be caused by multimode operation of the instrument laser source that might render the plane wave assumption in Mie theory invalid". Simulations by Hovenac and Lock (1993) also did not show significant suppression of Mie resonances for a multimodal FSSP laser beam.

The CDP laser is not multimodal; however, other nonidealities in the instrument performance could potentially result in a response that differs from the Mie calculations. We speculate that the optical model is insufficient for this particular instrument due to optical misalignment. As detailed in Appendix $\mathrm{A}$, if $\mathrm{SA}_{\mathrm{Q}}$ is out of alignment with the axis of the laser beam, this will result in a different range of collection angles for qualified droplets than the $4-12^{\circ}$ specification. Incomplete blocking of the primary forward scattering lobe can result in a dampening of the Mie resonance structure (if the misalignment is asymmetric relative to the axis of the laser beam) and also an increase in scattered intensity. The result of this type of misalignment was determined by integrating the Mie solution over different collection geometries. Much of the difference between measured and theoretical instrument response can be explained by a small misalignment. The sensitivity of instrument response to optical alignment emphasizes the need for detailed laboratory calibrations with water droplets.

\subsubsection{CDP counting response and sample area}

The standard CDP measurement provides a counting rate (droplets $\mathrm{s}^{-1}$ ). For a given position within $\mathrm{SA}_{\mathrm{Q}}$, the measured counting rate is in close agreement with the rate at which droplets were generated with the piezo-electric actuator $(250 \mathrm{~Hz})$. At the edges of $\mathrm{SA}_{\mathrm{Q}}$, a higher or a lower counting rate is possible due to electronic noise, which becomes important when the qualifier and sizer signals have nearly the same amplitude (Fig. $6 \mathrm{~b}$ and e). The effect of electronic noise is also expected to be greater when the pulse amplitude is smaller, as with smaller droplets. $\mathrm{SA}_{\mathrm{Q}}$ integrated from the calibrations depicted in Fig. 6 is $0.3 \pm 0.04 \mathrm{~mm}^{2}$ for both 12 and $22 \mu \mathrm{m}$ droplets, which is consistent with the manufacturer specifications. Although the counting rate varies significantly at the edges of $\mathrm{SA}_{\mathrm{Q}}$, the average counting rate within $\mathrm{SA}_{\mathrm{Q}}$ for both experiments is within $5 \%$ of the rate that droplets were generated.

\subsection{In-flight performance of the CDP}

\subsubsection{Liquid-only clouds}

During a transit flight on 29 March 2008 from Tampa, FL to Denver, $\mathrm{CO}$ in preparation for the ARCPAC campaign, multiple warm $\left(>0{ }^{\circ} \mathrm{C}\right)$, nonprecipitating clouds were intercepted at altitudes ranging from $900-1500 \mathrm{~m}$ over a period of about $1 \mathrm{~h}$. The observations made during this time period provide the basis for our LWC comparison. The measured droplet $D_{V}$ ranged from 4-17 $\mu \mathrm{m}$ for these clouds with an average $D_{V}$ of $11.9 \mu \mathrm{m}$ (after shifting the size bins by $2 \mu \mathrm{m}$, as described in Sect. 4.1.1), and droplet concentrations averaged $217 \mathrm{~cm}^{-3}$ with a maximum of $436 \mathrm{~cm}^{-3}$.

A bias was discovered in the CDP-LWC calculated from the measured droplet size distribution, as compared to the King-LWC. The CDP-LWC bias (Eq. 4) is strongly and linearly correlated with the measured droplet concentration (Fig. 7). This bias is consistent throughout the transit flight, and is also shown to be consistent on other flights where liquid water is present. Because of the droplet concentration dependence, we hypothesize that coincidence errors are responsible for the observed discrepancy in LWC. To quantify the expected coincidence errors, we first determine $\mathrm{SA}_{\mathrm{E}}$ in the laboratory and then perform Monte Carlo simulations to evaluate the effect of coincidence on both measured droplet concentrations and droplet sizes. The results of these simulations are reported in Sect. 4.3.

\subsubsection{Ice-only and mixed-phase clouds}

During an Arctic flight out of Fairbanks, AK on 1920 April 2008 we observed a much wider dynamic range in droplet concentrations than during the transit flight on 29 March. However, the clouds sampled during this Arctic flight were mixed-phase clouds, with ice crystals as large as $0.5 \mathrm{~mm}$ and King-LWC as high as $0.6 \mathrm{~g} \mathrm{~m}^{-3}$ simultaneously 

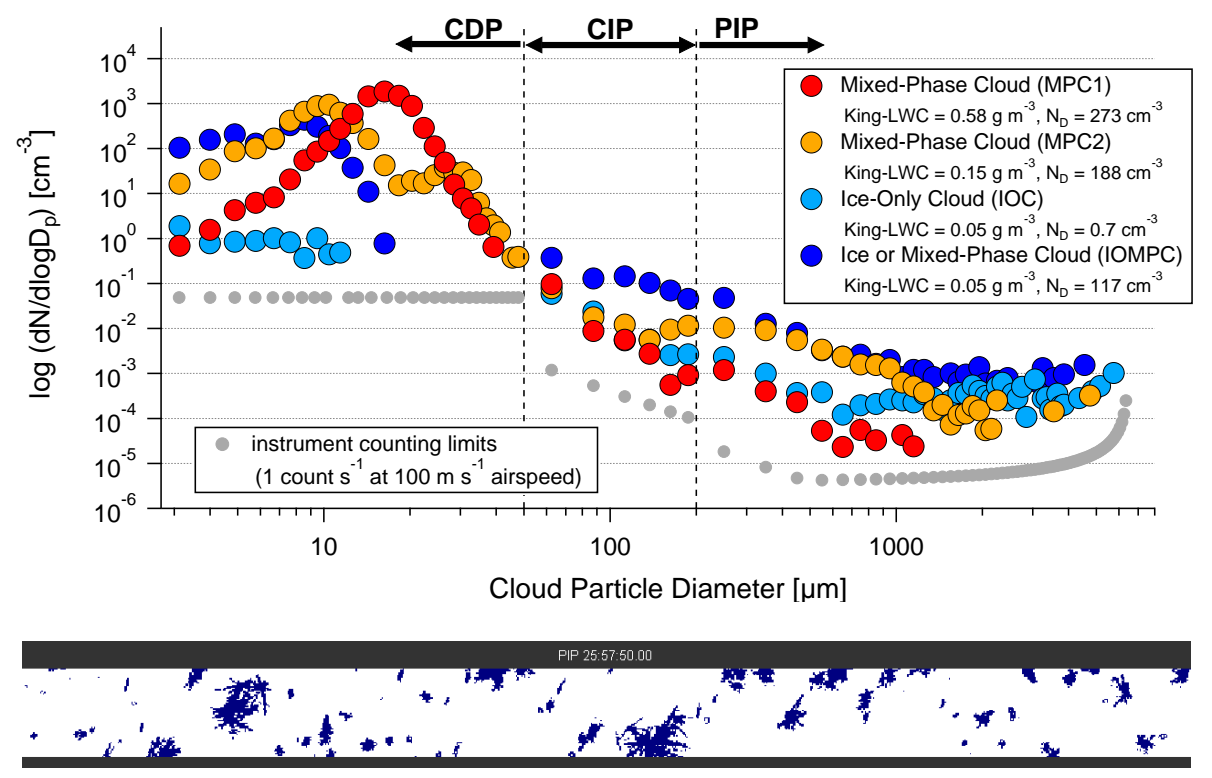

Fig. 8. Example cloud particle size distributions (derived from CDP, CIP and PIP measurements) for two Mixed-Phase Clouds (MPC), an Ice-Only Cloud (IOC) and an Ice or Mixed Phase Clouds (IOMPC) on the 19 April 2008 ARCPAC flight. Criteria for phase determination and definition of a cloud are presented in Sect. 3.3. Also shown are images from the PIP for the IOC.

observed. Ice crystals can lead to measurement artifacts in at least two ways, (1) by biasing the hot-wire LWC measurements and (2) by shattering on the arms of the CDP and producing many small ice particles that are counted as liquid droplets. In spite of this, the CDP-LWC bias for this flight showed a very similar trend with droplet concentration as did the liquid-only clouds sampled on the transit flight. Both flights are shown in Fig. 7. The robustness of this result over an even broader range of droplet concentrations gives us increased confidence that coincidence errors are driving the observed discrepancy between the CDP-LWC and the KingLWC. Furthermore, it suggests that ice crystal shattering did not dramatically affect the CDP-LWC bias observed for these mixed-phase clouds.

Figure 8 shows several different size distributions, combining measurements from the CDP $(3-50 \mu \mathrm{m})$, the CIP (50$200 \mu \mathrm{m})$ and PIP $(200-6000 \mu \mathrm{m})$ on the 19 April 2008 flight. The use of $1 \mathrm{~Hz}$ data in Fig. 8 sets the minimum concentration observable by each instrument; the instrument counting limits (grey) are plotted in addition to the ambient size distributions. Four examples are chosen: two mixed-phase clouds (MPC), an ice-only cloud (IOC) and a cloud that is either an ice or mixed-phase cloud (IOMPC). We would characterize the IOMPC as a MPC based on the first two cloud microphysical criteria outlined in Sect. 3.3, however the King-LWC for this sample was $<0.1 \mathrm{~g} \mathrm{~m}^{-3}$, and therefore we cannot state with confidence whether the particles detected by the CDP in this case are ice or liquid. However, the size distributions for the two MPCs and the IOMPC are quite similar, and they are consistent with the hypothesis that the IOMPC is simply further along in the process of glaciations/evaporation compared to MPC2.
In contrast, the IOC has a much lower number concentration, with a flat size distribution in the diameter range 3$10 \mu \mathrm{m}$, which may mean that the observed particles are a result of ice particle shattering. The IOC contained ice precipitation concentrations of $\sim 2 \mathrm{~L}^{-1}$ (for $D_{\mathrm{p}}>400 \mu \mathrm{m}$ ), including many large $(>1 \mathrm{~mm})$, lightly rimed, dendritic and aggregated ice crystals (as shown at the bottom of Fig. 8), which are expected to be the most fragile of any ice crystal habit (Pruppacher and Klett, 2000). Yet these conditions appear to have very little effect on the CDP size distribution, since observed concentrations are one to two orders of magnitude less than that in liquid clouds for any given size between 8 and $50 \mu \mathrm{m}$ in diameter. The measured CDP concentration is less than $0.7 \mathrm{~cm}^{-3}$ in this example, resulting in CDP-LWC of only $2 \times 10^{-5} \mathrm{~g} \mathrm{~m}^{-3}$. This level of uncertainty is more than sufficient for measuring liquid water droplets, which the CDP is designed to measure. However, although we classify this case as an IOC, in fact we cannot state with certainty whether the few particles observed by the CDP are in fact fragments of shattered ice crystals or evaporating droplets, since liquid droplets this small and few in number are not observable within the limits of the King-LWC probe. Despite this ambiguity, it appears that the ice crystal shattering artifact in the CDP does not significantly affect the cloud droplet measurements, even under the very poor conditions encountered for this example.

\subsection{Monte Carlo simulation results}

To evaluate the expected coincidence errors, we first determine $\mathrm{SA}_{\mathrm{E}}$ in the laboratory and then perform Monte Carlo simulations as described in Sect. 3.2. The calibrated $\mathrm{SA}_{\mathrm{E}}$ 

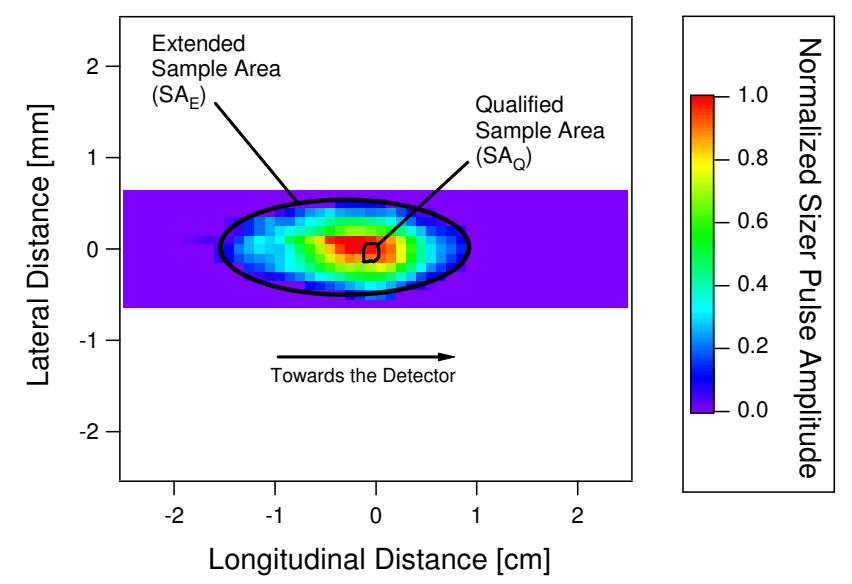

Fig. 9. Calibration of the Qualified Sample Area $\left(\mathrm{SA}_{\mathrm{Q}}\right)$ and $\mathrm{Ex}-$ tended Sample Area $\left(\mathrm{SA}_{\mathrm{E}}\right)$ for $22 \mu \mathrm{m}$ water droplets. Longitudinal and lateral directions shown in Fig. 3. The color scale shows the sizer pulse amplitude for droplets transiting through that location, normalized to the maximum sizer pulse amplitude at the center of the sizer DoF. Note that the longitudinal scale is a factor of ten times the lateral scale.

is much larger than $\mathrm{SA}_{\mathrm{Q}}\left(20.1 \mathrm{~mm}^{2}\right.$ vs. $\left.0.3 \mathrm{~mm}^{2}\right)$, spanning more than $2 \mathrm{~cm}$, nearly half the distance between the arms of the CDP (Fig. 9). This means that, for a droplet concentration of $500 \mathrm{~cm}^{-3}$, there are roughly 2 droplets on average within the extended sample volume $\left(20.1 \mathrm{~mm}^{2} \times 0.2 \mathrm{~mm}\right)$ at any given time, and the probability for coincidence events is therefore very high.

The simulations allow us to evaluate the effect of coincidence on droplet concentration and droplet size. Figure 10 shows examples of simulated sizer and qualifier signals, with the prescribed qualified droplet positioned at the center of the $100 \mu$ s time window. This is the raw output of the simulations. We describe a "perfect" instrument as one in which the pulse amplitude is unaffected by coincidence or spatially heterogeneous sizing response (Sect 2.5.2), and is instead directly and unambiguously related to droplet size according to the power law relationship shown in Fig. 4. In actuality, for an imperfect instrument, three different results are possible:

1. The qualified droplet is under or oversized after transiting through a position within $\mathrm{SA}_{\mathrm{Q}}$ with a lower response (Fig. 10a). For the particular case shown, the droplet size is unaffected by coincidence because no coincident droplets happen to arrive at exactly the same time as the qualified droplet. However, the transit time for this case is slightly longer than it would have been, because coincidence extends the amount of time that the sizer signal remains above an electronic threshold.
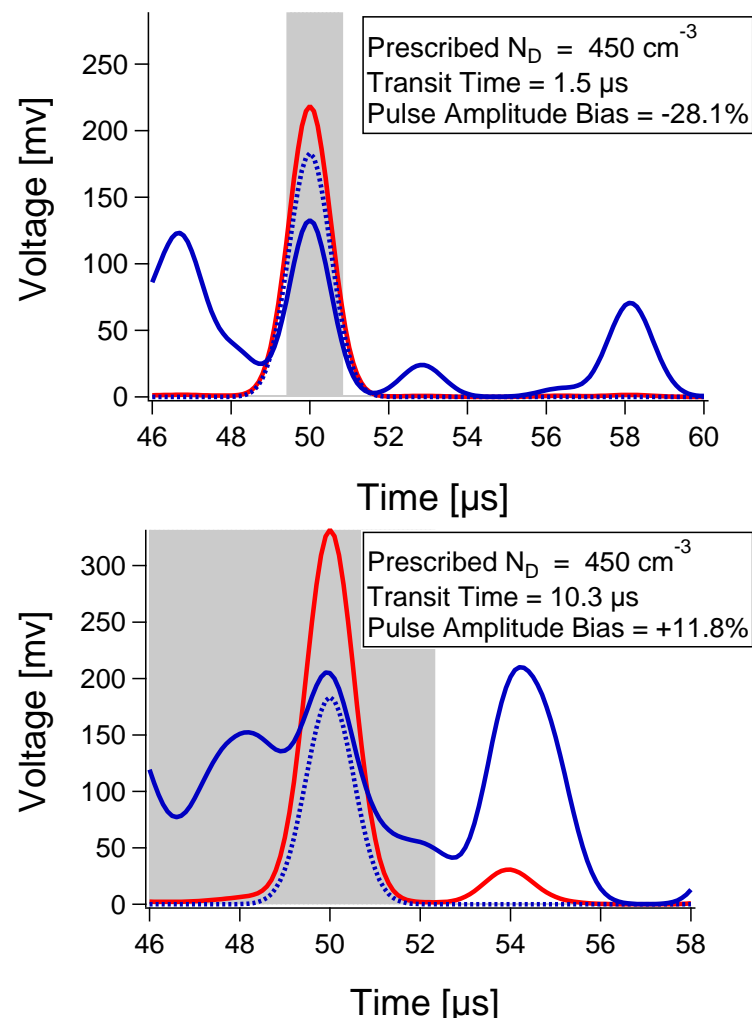

(a)
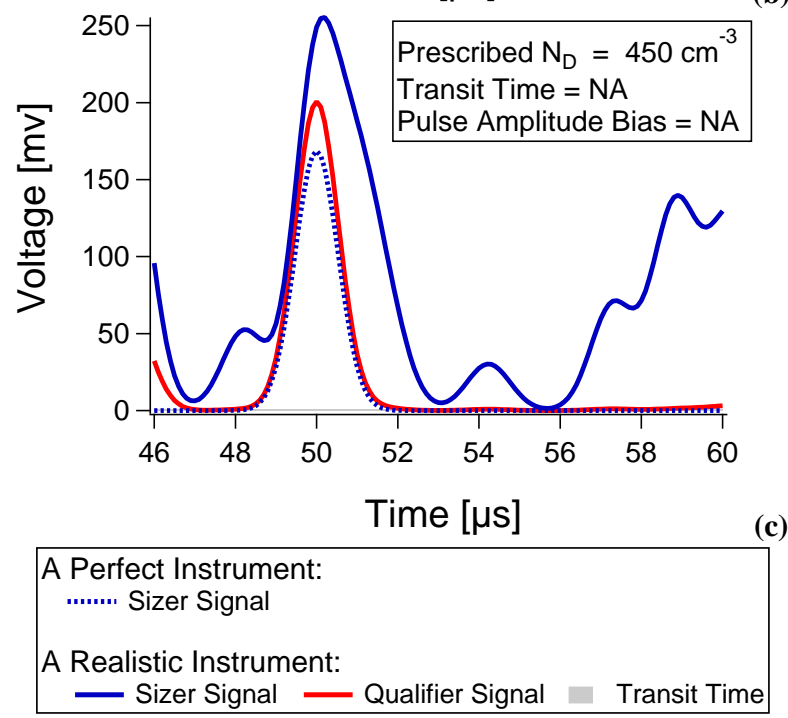

Fig. 10. Simulated electronic pulses for three different scenarios: (a) qualified droplet is undersized due to transit through a location of less sensitive instrument response within $\mathrm{SA}_{\mathrm{Q}}$, (b) qualified droplet is oversized due to coincident droplets, (c) qualified droplet is not counted due to coincident droplets.

2. The droplet is oversized due to a coincident droplet that scatters additional light into the sizer, but not necessarily into the qualifier (Fig. 10b). In the particular case shown, the transit time is also much longer due to several other coincident droplets. 


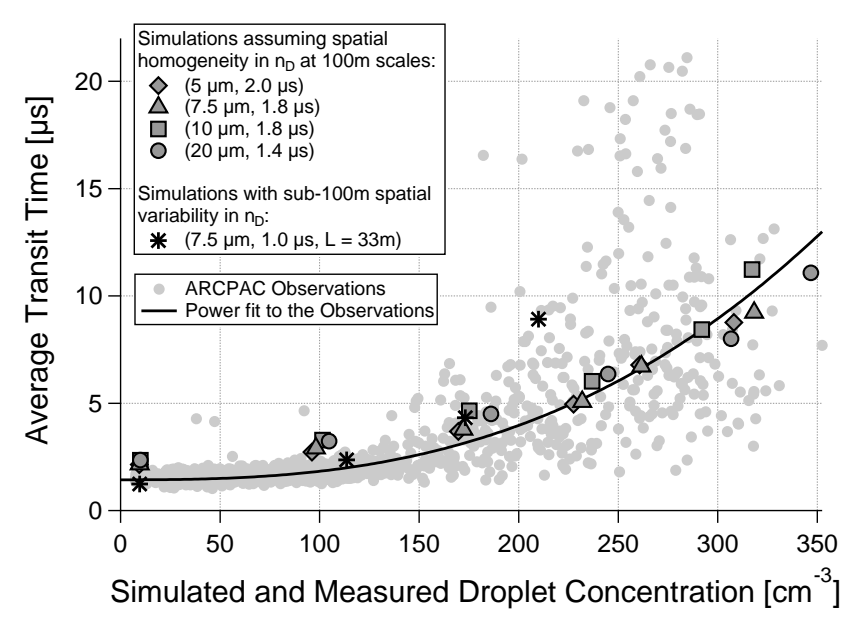

Fig. 11. Simulated and observed average transit times as a function of the simulated and measured droplet concentrations. A range of prescribed droplet sizes are chosen $(5,7.5,10$ and $20 \mu \mathrm{m})$ in the simulations, and the pulse widths are then determined for best agreement with the average transit times observed. The average transit times thereby provide a constraint on the pulse widths used in the simulations, and also a constraint on the coincidence errors for a given droplet size. The set of simulations including sub-sample variability in droplet concentrations results in greater coincidence errors, even though shorter pulse widths are used, and produces better agreement with the average transit time observations at both low and high droplet concentrations.

3. The sizer signal exceeds the qualifier signal due to a coincident droplet, resulting in erroneous rejection of the qualified droplet (Fig. 10c). The maximum oversizing error due to coincidence is constrained by the qualifier signal; when this constraint is exceeded, droplets are undercounted.

The major constraint on the prescribed pulse widths used in the simulations is the average transit times measured during the ARCPAC flights. Figure 11 shows the average transit times derived from the simulations compared to the observations, with pulse widths chosen in the simulations for a given droplet size to obtain the best correlation to the average transit times observed. For each set of prescribed droplet sizes and pulse widths, the simulations reproduce the general trend of increasing transit times at higher droplet concentrations. At high droplet concentrations, the simulated transit times agree well with the observations. However, at the low droplet concentrations the simulated transit times are greater than the observations, suggesting that shorter pulse widths should be used. If sub-sample variability is considered, shorter pulse widths can be used without reducing the average transit time at high droplet concentrations. Heterogeneity in droplet concentrations over time intervals smaller than the $1 \mathrm{~s}$ sampling period will always increase the coincidence errors for a given measured droplet concentration. Conversely, the same coincidence error can be obtained using smaller pulse widths, if

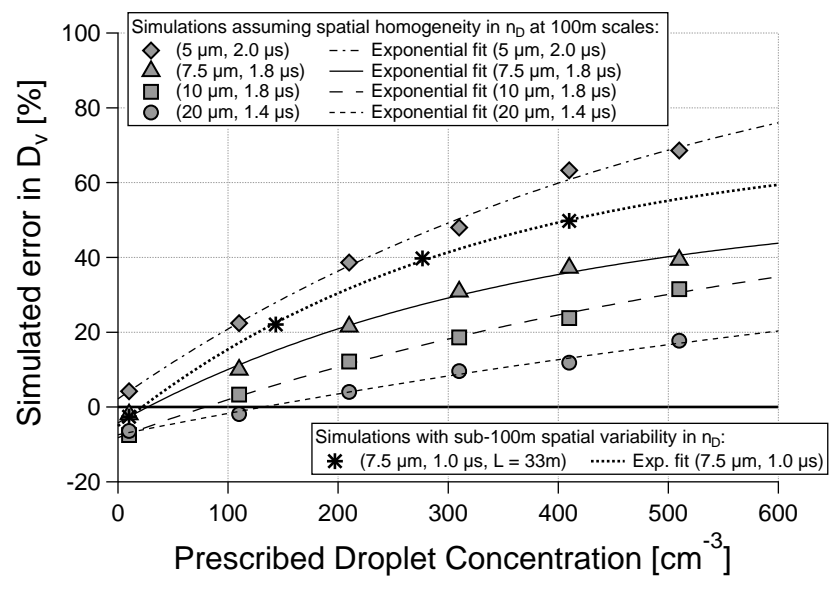

Fig. 12. Simulated error in volume mean diameter $\left(D_{V}\right)$ as a function of prescribed droplet concentrations. Droplet sizing uncertainty at low droplet concentrations is $<10 \%$. Smaller droplets exhibit greater relative oversizing errors due to coincidence. Sub-sample variability in droplet concentrations also increases the oversizing error.

sub-sample variability is considered. We ran additional simulations with a droplet counting rate that varied within the 1 s sampling period, by assuming that all droplets were intercepted during the first third of the sampling period $(L=33 \mathrm{~m}$, where $L$ is the length scale of the cloud filament), using a Poisson distribution of interarrival times for all intercepted droplets. The result is shorter transit times at low concentrations and longer transit times at high droplet concentration, which produces better agreement with the observed average transit times (Fig. 11). The simulations suggest that $L$ is typically between $33 \mathrm{~m}$ and $100 \mathrm{~m}$ for the clouds sampled during ARCPAC. However, it is impossible to resolve or correct for variability in droplet concentrations at horizontal scales smaller than $100 \mathrm{~m}$ for the ARCPAC dataset, since sampling rates higher than $1 \mathrm{~Hz}$ were not obtained.

Figure 12 shows the simulated bias in volume mean diameter, $D_{V}$, for these simulations. Exponential fits of the simulated $D_{V}$ error as a function of the prescribed droplet concentration are shown for each set of prescribed droplet sizes and pulse widths; the slope of these lines decreases with increasing droplet size, as expected due to the nonlinear relationship between forward scatter intensity and droplet size. The oversizing bias due to coincidence ranges from $5 \%$ per $100 \mathrm{~cm}^{-3}$ droplet concentrations to as high as $20 \%$ per $100 \mathrm{~cm}^{-3}$, for droplet sizes from $\sim 5 \mu \mathrm{m}$ to $\sim 20 \mu \mathrm{m}$, resulting in as much as $60 \%$ oversizing bias at droplet concentrations of $400 \mathrm{~cm}^{-3}$. Undercounting resulting from coincidence is similarly dramatic, as shown in Fig. 13, with undercounting as high as $50 \%$ in the simulations for prescribed droplet concentrations of $400 \mathrm{~cm}^{-3}$. Since the pulse widths and interarrival times of individual droplets during in-flight operation are not known, these results show the expected range of droplet sizing errors, given our uncertainty in the width of the CDP laser (in the 


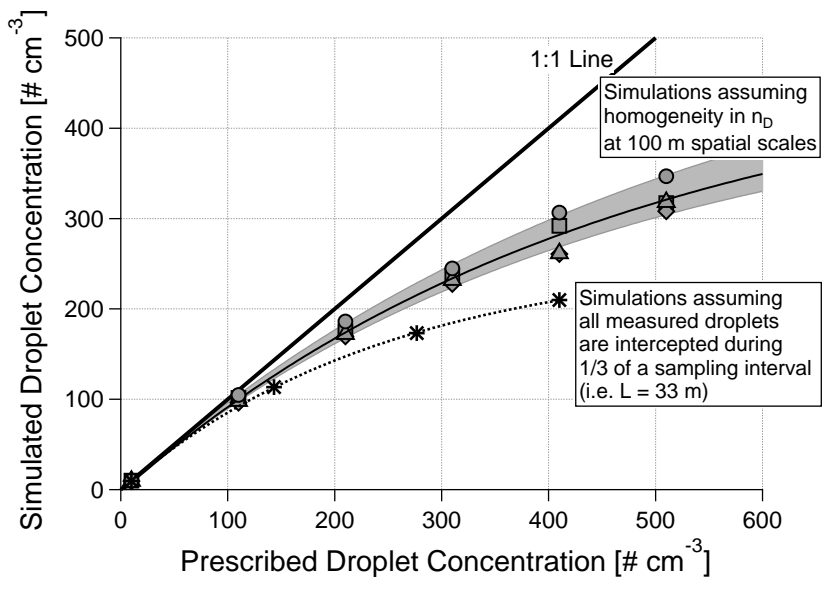

Fig. 13. Simulated droplet concentrations as a function of prescribed droplet concentrations. All droplet sizes exhibit roughly the same degree of undercounting. Sub-sample variability in droplet concentrations increases the undercounting error.

direction of motion), which the coincidence error is highly sensitive to. The laser width is parameterized by varying the pulse widths, which are constrained by the average transit times observed.

Figure 14 shows simulated droplet size distributions at different prescribed droplet concentrations. At low droplet concentrations (Fig. 14a) the simulated droplet size distribution is not significantly affected by coincidence, and the breadth of the simulated distribution is instead controlled by the spatially heterogeneous sizing response of the CDP to droplets within $\mathrm{SA}_{\mathrm{Q}}$. At higher droplet concentrations, the effect of coincidence broadens and shifts the droplet size distribution to larger sizes (Fig. 14b). Ambient droplet size distributions observed during a flight during ARCPAC are shown for comparison to the simulated size distributions, in Fig. 14a and b. The simulated and measured size distributions and CDPLWC biases are comparable, suggesting that the model assumptions (i.e. prescribed droplet distributions, pulse widths and interarrival times) are realistic for these examples.

For direct comparison to the all of the ambient observations (Fig. 7), the simulated CDP-LWC bias is calculated and plotted as a function of the simulated droplet concentration (Fig. 15). At low droplet concentrations the simulations are unable to explain the negative CDP-LWC bias observed, since the maximum sizing uncertainty expected, based on the calibrations, is $<10 \%$ (corresponding to a CDPLWC bias of $-33 \%$ ). This suggests that the CDP-LWC bias observed is affected by a positive bias in the KingLWC measurements for these mixed-phase clouds. Since the maximum bias expected for the King-LWC measurements is $+0.08 \mathrm{~g} \mathrm{~m}^{-3}$, and the minimum King-LWC measurement reported is $0.1 \mathrm{~g} \mathrm{~m}^{-3}$, the CDP-LWC bias could be as low as $-80 \%$. It is also possible that the CDP consistently undersizes droplets during in-flight sampling due to insufficient electronic response time at aircraft velocities $\left(\sim 125 \mathrm{~m} \mathrm{~s}^{-1}\right)$. We are currently unable to evaluate this possibility, since the calibrations were performed at $<45 \mathrm{~m} \mathrm{~s}^{-1}$. The CDP-LWC bias observed at low droplet concentrations is consistent with undersizing of droplets by $11 \%$, or roughly one size bin. However, a positive bias in the King-LWC measurements is expected in the presence of high ice mass and/or high supercooled water content; therefore, if slow electronic response has an effect on the measured droplet size, we expect that the effect is $<11 \%$ at $125 \mathrm{~m} \mathrm{~s}^{-1}$.

Extended coincidence causes the simulated CDP-LWC bias to increase with droplet concentration in Fig. 15. The slope of this relationship is strongly dependent on the droplet size prescribed in the simulations. Simulations with droplet diameters of 7.5-15 $\mu \mathrm{m}$ appear to explain the observed slope, given prescribed pulse widths of $1.4-2.0 \mu$ s constrained by average transit time observations. During ARCPAC, observed $D_{V}$ ranged from $11 \mu \mathrm{m}$ on average for measured droplet concentrations greater than $300 \mathrm{~cm}^{-3}$ to $15 \mu \mathrm{m}$ on average for droplet concentrations less than $100 \mathrm{~cm}^{-3}$. The simulations indicate that during events of high droplet concentrations, the droplet size is actually much smaller and the distribution is narrower than the measurements indicate, as illustrated in Fig. 14b.

\section{Summary and conclusions}

Laboratory calibrations of the CDP sample area and droplet sizing were performed using water droplets of known size and concentration. The sample area was determined for 12 and $23 \mu \mathrm{m}$ droplets, and both were consistent with the instrument specifications. Although calibrations with PSL and glass beads were consistent with theoretical instrument response, liquid water droplet calibrations were not, and necessitated a $2 \mu \mathrm{m}$ shift in the manufacturer's calibration. Much of this response shift may be attributable to an asymmetric misalignment of the optical mask relative to the axis of the laser beam.

Comparison with an independent measure of liquid water content (LWC) in-flight during the ARCPAC campaign suggests a bias in the droplet size and/or droplet concentration measured by the CDP that are beyond the uncertainties determined from the laboratory calibrations. Observations during ARCPAC suggest that ice crystal shattering does not substantially affect the CDP size distribution measurements in the mixed-phase and ice-only clouds encountered. Since the bias in CDP-LWC is strongly concentration dependent, and consistent for both liquid and mixed-phase clouds, we hypothesize that the discrepancy is a result of coincidence, when two or more droplets pass through the CDP laser beam within a very short time of each other. The coincidence error is evaluated in terms of an extended sample area, the area in which individual droplets can affect the sizing detector without necessarily registering as a valid droplet, which was also calibrated using water droplets. 

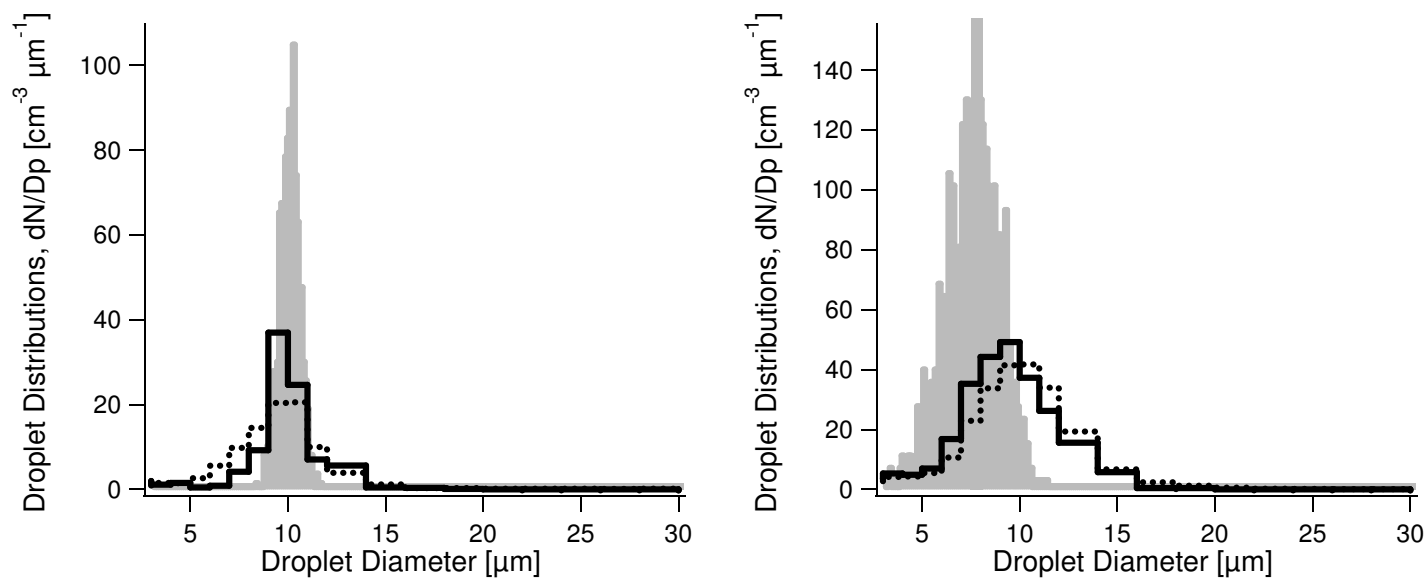

\begin{tabular}{|l|}
\hline Prescribed distribution \\
\\
$110 \mathrm{~cm}^{-3}, 10( \pm 5 \%) \mu \mathrm{m}, 1.8 \mu$ s pulse width \\
Simulated distribution \\
$101 \mathrm{~cm}^{-3}$, CDP-LWC bias $=1.7 \%$ \\
$\ldots$. Measured distribution \\
(at 03:15:04 on 20 April 2008 ) \\
$102 \mathrm{~cm}^{-3}$, CDP-LWC bias $=0.93 \%$
\end{tabular}

(a)

\begin{tabular}{|c|c|}
\hline \multicolumn{2}{|c|}{ Prescribed distribution } \\
\hline & $410 \mathrm{~cm}^{-3} 75(+10 \%)$ um 1.8 us \\
\hline & Simulated distribution \\
\hline & $275 \mathrm{~cm}^{-3}$, CDP-LWC bias $=58 \%$ \\
\hline ..... & $\begin{array}{l}\text { Measured distribution } \\
\text { (at } 00 \cdot 22 \cdot 45 \text { on } 20 \text { April } 2008 \text { ) }\end{array}$ \\
\hline & $267 \mathrm{~cm}^{-3}$, CDP-LWC bias $=60 \%$ \\
\hline
\end{tabular}

(b)

Fig. 14. Prescribed and simulated droplet size distributions at droplet concentrations of (a) $110 \mathrm{~cm}^{-3}$ and (b) $410 \mathrm{~cm}^{-3}$. The simulated CDP-LWC bias for each of these cases is consistent with the range of CDP-LWC biases observed at a given droplet concentration during the ARCPAC flights. Also shown for comparison are $1 \mathrm{~Hz}$ droplet size distributions at comparable droplet concentrations, as measured during the 19 April 2008 flight.

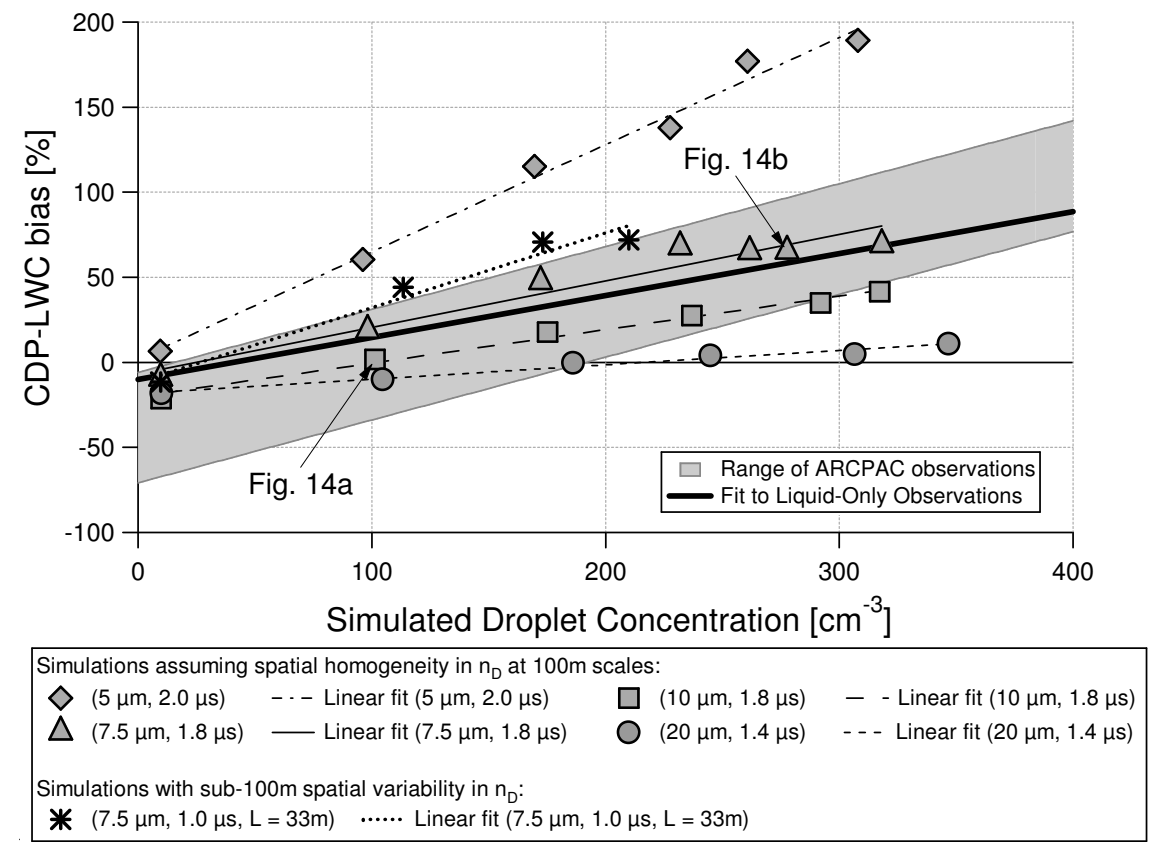

Fig. 15. Simulated bias in CDP-LWC as a result of coincidence errors, plotted as a function of simulated droplet concentrations. Plotted for comparison is the observed range (one standard deviation) in CDP-LWC bias versus droplet concentration for the mixed-phase clouds sampled during ARCPAC and the linear fit to the liquid-only clouds sampled on 29 March 2008. Compare to actual data in Fig. 7. 
A Monte Carlo simulation was developed to estimate the effect of coincidence on the measured droplet size distributions based on laboratory calibrations of the extended sample area using water droplets. The simulations show that coincidence errors can explain two distinct trends in the ambient observations: (1) the observed increase in CDP-LWC bias as a function of droplet concentrations, and (2) the increase in average transit time as a function of droplet concentrations. Coincidence was found to be significant for the CDP at droplet concentrations even as low as $200 \mathrm{~cm}^{-3}$. We estimate that $60 \%$ oversizing and $50 \%$ undercounting due to coincidence can occur in the CDP at droplet concentrations of $400 \mathrm{~cm}^{-3}$, and expect that these biases are dependent on the droplet size. We show that the simulations can replicate specific observed droplet size distributions and concentrations while also producing CDP-LWC biases consistent with the observations. However, the simulations assuming a Poisson distribution of interarrival times distributed evenly throughout the entire $\sim 100 \mathrm{~m}$ sample are also unable to reproduce many of the very high average transit times observed. This suggests that there is, at times, an even greater effect of coincidence than expected. We show that spatial variability in ambient droplet concentrations can produce greater coincidence errors, suggesting that the clouds sampled during ARCPAC exhibit significant spatial variability at horizontal scales smaller than can be resolved for the $1 \mathrm{~Hz}$ measurements obtained. By incorporating sub-sample variability in droplet concentrations into the simulations, we are able to simultaneously account for the range of CDP-LWC biases, droplet sizes, droplet concentrations and average transit times observed during ARCPAC. However, we emphasize that, ultimately, the simulations provide only plausible scenarios and general tendencies, rather than absolute correction factors for specific size distribution measurements, due to insufficient constraints on the actual size and pulse widths of individual droplets, as well as unresolved spatial heterogeneity in droplet concentrations.

Having identified a weakness in the CDP optical design, the primary goal at this stage is to minimize coincidence errors as much as possible by physically modifying the CDP optics to limit the area viewable by the sizing detector. As long as the qualified sample area is not affected, such instrument modification will not affect the instrument counting statistics. Instrument modifications have been implemented, and preliminary investigation indicates that the coincidence errors have been substantially reduced. The performance of the modified instrument is being studied and will be the subject of a future publication.

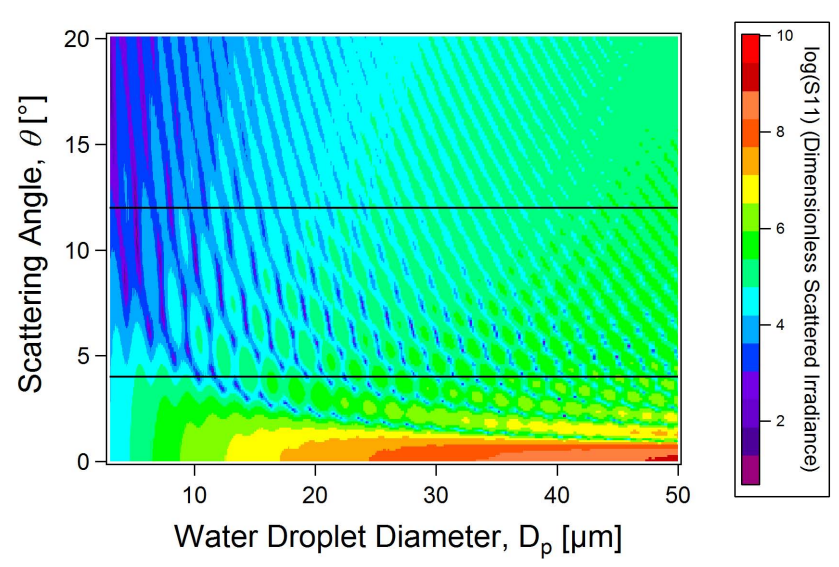

Fig. A1. Logarithm of the dimensionless scattered irradiance (S11) as a function of scattering angle and droplet diameter, from Mie Theory.

\section{Appendix A}

\section{Calculation of the effects of asymmetric optical misalignment on instrument performance}

The dimensionless scattered irradiance, S11, is calculated from Bohren and Huffman (1983). Figure A1 shows S11 as a function of scattering angle between 0 and $20^{\circ}$ (with $\Delta \theta=0.1^{\circ}$ angular resolution) and as a function of a water droplet diameter between 3 and $50 \mu \mathrm{m}$ (with size resolution $\left.\Delta D_{\mathrm{p}}(\mathrm{nm})=0.00577 D_{\mathrm{p}}(\mathrm{nm})-17.3\right)$.

The radiant power, $P$, scattered by a particle illuminated by a plane wave laser is described by Eq. (A1), assuming an unpolarized source with incident intensity $I_{\mathrm{O}}$ and wavelength $\lambda$.

$P=I_{\mathrm{o}}\left(\frac{\lambda}{2 \pi}\right)^{2} \int_{0}^{2 \pi} \int_{\theta 1}^{\theta 2} \mathrm{~S} 11 \sin \theta d \theta d \phi=I_{\mathrm{o}}\left(\frac{\lambda}{2 \pi}\right)^{2} \mathrm{DI}$ (A1)

where $d \Omega=\sin \theta d \theta d \phi$ is the solid angle of integration and DI is the double integral term. For a spherical particle, S11 obeys symmetry over $\phi$. If the collection geometry is aligned with the axis of the laser beam, Eq. (A1) can then be simplified since the integrals over $\phi$ and $\theta$ are independent (Hovenac and Lock, 1993). In that case the integration limits $\theta_{1}$ and $\theta_{2}$ are simply the minimum and maximum scattering angles detected (i.e. $4^{\circ}$ and $12^{\circ}$, respectively). However, if the collection geometry is not aligned with the axis of the laser beam, the integration limits over $\theta$ become dependent on $\phi$, making the equation more difficult to solve. We present a method for numerically integrating the DI, for use when the collection geometry is not aligned with the axis of the laser beam.

First we configure an $x-y$ grid in Cartesian coordinates with $N_{\mathrm{x}} \Delta x>2 R$ and $N_{\mathrm{y}} \Delta y>2 R$, where $N_{\mathrm{x}}$ and $N_{\mathrm{y}}$ are the number of horizontal and vertical points in the grid, $\Delta x$ and $\Delta y$ are the horizontal and vertical resolution of the grid, and 


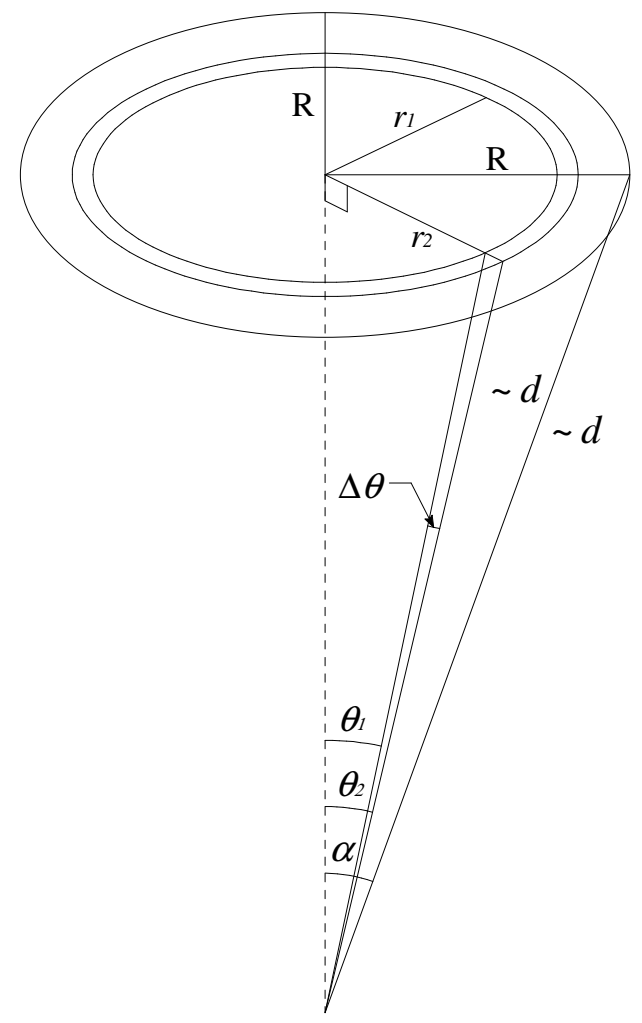

Fig. A2. Geometry used to calculate the radiant power intercepting a flat plane at some distance $d$ from a scattering particle.

$R=d \sin \alpha$ is the maximum radius of the projected scattering function at some distance $d$ from the droplet (Fig. A2). If the distance between $\mathrm{SA}_{\mathrm{Q}}$ and the beam dump is $d \sim 4 \mathrm{~cm}$ and the maximum scattering angle collected is $\alpha=20^{\circ}$ (allowing for a significant misalignment, since nominally $\alpha=12^{\circ}$ ), then $R \sim 14 \mathrm{~mm}$.

Next, we set the laser beam axis to the center of the grid, at $x_{\mathrm{o}}=N_{\mathrm{x}} \Delta x / 2$ and $y_{\mathrm{o}}=N_{\mathrm{y}} \Delta y / 2$. Any given $(x, y)$ coordinate in the grid corresponds to a circle of radius $r$ with origin at $\left(x_{\mathrm{o}}, y_{\mathrm{o}}\right)$, where

$r=\sqrt{\left(y-y_{\mathrm{o}}\right)^{2}+\left(x-x_{\mathrm{o}}\right)^{2}}$

We then identify the annulus with $r_{1}<r<r_{2}$ corresponding to $\Delta \theta=\theta_{2}-\theta_{1}=0.1^{\circ}$, where $r_{2} \sim d \sin \theta_{2}$ and $r_{1} \sim d \sin \theta_{1}$ (Fig. A2). The grid resolution is chosen such that $\Delta x=\Delta y<$ $d \sin \Delta \theta$. The annulus corresponds to small range of collection angles, $\Delta \theta$, and a given droplet size, and therefore corresponds to a constant value for S11 (Fig. A1).

To numerically approximate the radiant power intercepted by a given $\Delta x, \Delta y$ pixel, we normalize DI (evaluated over the annulus with $\Delta \theta=\theta_{2}-\theta_{1}=0.1^{\circ}$ ) by the ratio of the pixel area $\left(A_{\mathrm{p}}\right)$ and the area of the annulus $\left(A_{\mathrm{a}}\right)$ within which the pixel lies.

$A_{\mathrm{p}}=\Delta x \Delta y$
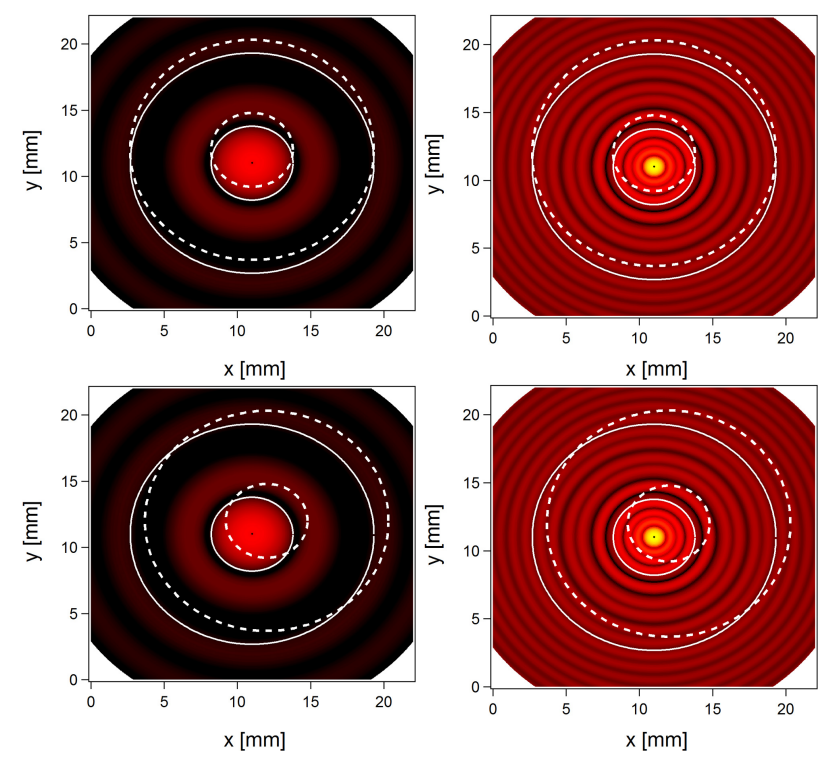

Fig. A3. Spatial distribution of scattered radiant power for $10 \mu \mathrm{m}$ (left) and $40 \mu \mathrm{m}$ (right) droplets, respectively, projected on a flat plane at $4 \mathrm{~cm}$ distance from the droplet. The solid white circles represent $4-12^{\circ}$ symmetric collection angles. The dotted white circles represent the CDP light-collection geometry accounting for a lateral misalignment of $1 \mathrm{~mm}$ in $y$ (top) and $1 \mathrm{~mm}$ in both $x$ and $y$ (bottom) for qualified droplets relative to the intended optical alignment.

$A_{\mathrm{a}}=\pi\left[\left(r_{2}\right)^{2}-\left(r_{1}\right)^{2}\right]$

The result is illustrated in Fig. A3 for $10 \mu \mathrm{m}$ (left) and $40 \mu \mathrm{m}$ (right) droplets, with the color scale indicating the logarithm of $\left(A_{\mathrm{p}} / A_{\mathrm{a}}\right)$ DI. This scattering pattern represents the spatial distribution of radiant power scattered by a droplet that would be intercepted by a photodetector if placed at the location of the dump spot.

After the scattering pattern is obtained, integration over any collection geometry is possible, by simply summing all pixels that fall within a given area. First we test this numerical method by integrating over the original collection geometry (i.e. $4-12^{\circ}$ ), and the agreement with DI from Eq. (A1) is within $1 \%$. Then we shift the collection geometry laterally by $\Delta y=1 \mathrm{~mm}$ (Fig. A3, top), representing a lateral displacement of the optics relative to the axis of the laser beam. To integrate over this new collection geometry, we first shift the reference position $\left(x_{0}, y_{0}\right)$ by $\Delta y$, so that the origin aligns with the new (misaligned) collection geometry. Then we use Eq. (A2) for each coordinate in the scattering pattern to determine if $(x, y)$ falls within $R_{1}<r<R_{2}$, where $R_{1}=d \sin \left(4^{\circ}\right)$ and $R_{2}=d \sin \left(12^{\circ}\right)$. The same method is used to integrate the scattering pattern for a misalignment in both $x$ and $y$ (Fig. A3, bottom).

For these two examples, the response curve (Fig. A4) is calculated using this numerical method to account for varying degrees of misalignment between the optics and the axis of the laser beam. Each dark blue and light blue point in 

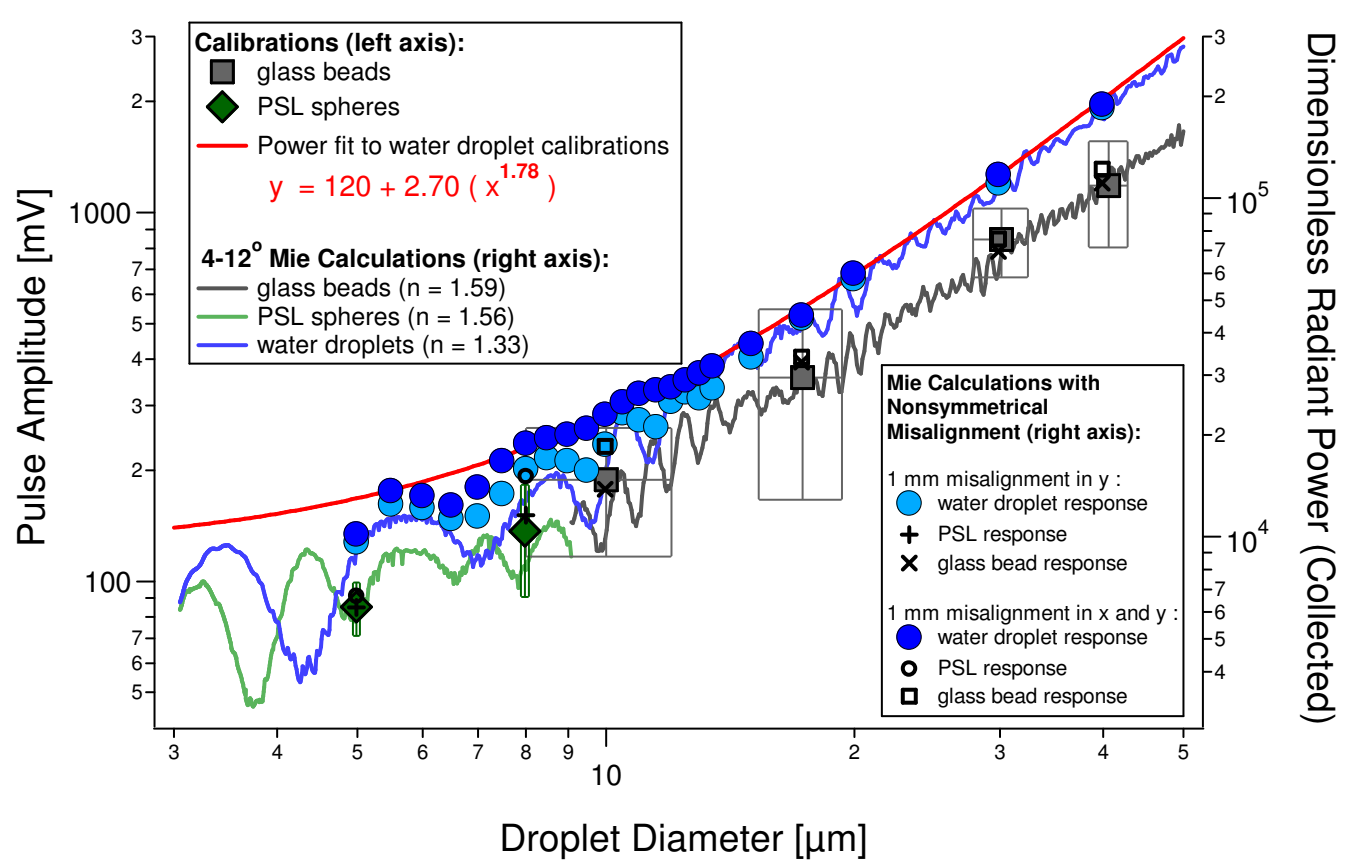

Fig. A4. The calibrated response of the CDP to PSL and glass beads, and the calculated response for PSL, glass beads and water droplets assuming that forward scattered light $4-12^{\circ}$ is collected by the sizing detector. The light blue dots show the modeled CDP response for water droplets given a $1 \mathrm{~mm}$ misalignment in the $y$-dimension (laterally across the laser, and perpendicular to the droplet trajectories). The dark blue dots similarly show the modeled CDP response for water droplets given a slightly greater misalignment. The fit to the water droplet calibrations is shown for comparison. The calculated responses to PSL and glass beads (given these two examples of misalignment) are also shown, and often agree well with the PSL and glass bead calibrations.

Fig. A4 is derived by integrating a different scattering pattern for a given droplet size. Calculations were also made for the response of the misaligned instrument to glass beads $(n=1.59)$ and PSL spheres $(n=1.56)$, for the same sizes used in the glass bead and PSL calibrations. The continuous response curves calculated using DI from Eq. A1 integrated over $4-12^{\circ}$ are also shown for comparison. For both examples of misalignment (Fig. A3), the result is greater radiant power collected for droplet sizes $<\sim 12 \mu \mathrm{m}$, with little affect on the scattering response for larger droplets. Both examples also result in some degree of dampening of the Mie oscillations, bringing the Mie calculations in closer agreement with the water droplet calibrations. The glass bead and PSL calculations also agree well in almost all cases with the calibrations, and misalignment even appears to explain some of the disagreement between the calibrations and the original calculations. It is interesting to note that improved instrument performance may result from deliberate misalignment of the optics.

Acknowledgements. This work was supported by the National Oceanic and Atmospheric Administration (NOAA) climate and air quality programs. We thank Jorge Delgado and the NOAA Aircraft Operations Center for allowing use of their equipment and for technical support in the field. We thank Bill Dubé and Matt Richardson for practical laboratory support. Special thanks to Alexei Korolev, Dan Murphy, Al Cooper and Jeff Peischl for critical comments, discussion and advice. S. Lance acknowledges the National Research Council for a Research Associateships Program fellowship awarded in January 2008.

\section{Disclaimer}

US government work not protected by US copyright laws. The use of trade, firm, or corporation names in this publication is for the information and convenience of the reader. Such use does not imply an official endorsement or approval by the University of Colorado, the United States Department of Commerce, the National Institute of Standards and Technology, or the National Oceanic and Atmospheric Administration of any product or service to the exclusion of others that may be suitable.

Edited by: M. Wendisch

\section{References}

Alekseev, G. V., Danilov, A. I., Kattsov, V. M., Kuz'mina, S. I., and Ivanov, N. E.: Changes in the Climate and Sea Ice of the Northern Hemisphere in the 20th and 21st Centuries from Data of Observations and Modeling, Atmos. Oceanic Phys., 45(6), 723735, 2009.

Baumgardner, D.: An Analysis and Comparison of Five Water Droplet Measuring Instruments, J. Climate Appl. Met., 22, 891910, 1983. 
Baumgardner, D. and Spowart, M.: Evaluation of the Forward Scattering Spectrometer Probe. Part III: Time Response and Laser Imhomogeneity Limitations, J. Atmos. Oceanic Technol., 7, 666-672, 1990.

Baumgardner, D., Strapp, W., and Dye, J. E.: Evaluation of the Forward Scattering Spectrometer Probe - Part II: Corrections for coincidence and dead-time losses, J. Atmos. Oceanic Technol., 2, 626-632, 1985.

Biter, C. J., Dye, J. E., Huffman, D., and King, W. D.: The DropSize Response of the CSIRO Liquid Water Probe, J. Atmos. Oceanic Technol., 4, 359-367, 1987.

Bohren, C. F. and Huffman, D. R.: Absorption and Scattering of Light by Small Particles, John Wiley and Sons, 1983.

Brenguier, J. L., Baumgardner, D., and Baker, B.: A Review and Discussion of Processing Algorithms for FSSP Concentration Measurements, J. Atmos. Oceanic Technol., Notes and Correspondence, 11, 1409-1414, 1994.

Brenguier, J. L., Bourrianne, T., de A. Coelho, A., Isbert, J., Peytavi, R., Trevarin, D., and Weschler, P.: Improvements of Droplet Size Distribution Measurements with the Fast-FSSP (Forward Scattering Spectrometer Probe), J. Atmos. Oceanic Technol., 15, 1077-1090, 1998.

Brock, C. A., Cozic, J., Bahreini, R., Froyd, K. D., Middlebrook, A. M., McComiskey, A., Brioude, J., Cooper, O. R., Stohl, A., Aikin, K. C., de Gouw, J. A., Fahey, D. W., Ferrare, R. A., Gao, R.-S., Gore, W., Holloway, J. S., Hübler, G., Jefferson, A., Lack, D. A., Lance, S., Moore, R. H., Murphy, D. M., Nenes, A., Novelli, P. C., Nowak, J. B., Ogren, J. A., Peischl, J., Pierce, R. B., Pilewskie, P., Quinn, P. K., Ryerson, T. B., Schmidt, K. S., Schwarz, J. P., Sodemann, H., Spackman, J. R., Stark, H., Thomson, D. S., Thornberry, T., Veres, P., Watts, L. A., Warneke, C., and Wollny, A. G.: Characteristics, sources, and transport of aerosols measured in spring 2008 during the aerosol, radiation, and cloud processes affecting Arctic climate (ARCPAC) project, Atmos. Chem. Phys. Discuss., 10, 27361-27434, doi:10.5194/acpd-10-27361-2010, 2010.

Burnet, F. and J.-L. Brenguier, Comparison between Standard and Modified Forward Scattering Spectrometer Probes during the Small Cumulus Microphysics Study, J. Atmos. Oceanic Technol., 19, 1516-1531, 2002.

Conant W. C., VanReken, T. M., Rissman, T. A., Varutbangkul, V., Jonsson, H. H., Nenes, A., Jimenez, J. L., Delia, A. E., Bahreini, R., Roberts, G. C., Flagan, R. C., and Seinfeld, J. H.: Aerosolcloud drop concentration closure in warm cumulus, J. Geophys. Res., 109, D13204, doi:10.1029/2003JD004324, 2004.

Cooper, W. A.: Effects of Coincidence on Measurements with a Forward Scattering Spectrometer Probe, J. Atmos. Ocean. Technol., 5, 823-832, 1988.

Curry, J. A., Schramm, J. L., and Ebert, E. E.: Impact of Clouds on the Surface Radiation Balance of the Arctic Ocean, Meteorol. Atmos. Phys., 51, 197-217, 1993.

Curry, J. A. and Ebert, E. E.: Annual Cycle of Radiation Fluxes over the Arctic Ocean: Sensitivity to Cloud Optical Properties, J. Climate, 5, 1267-1280, 1992.

Diehl, K., Huber, G., Mitra, S. K., and Wendisch, M.: Laboratory Studies of Scattering Properties of Polluted Cloud Droplets: Implications for FSSP Measurements, J. Atmos. Oceanic Technol., 25, 1894-1898, 2008.

Feind, R. E., Detwiler, A. G., and Smith, P. L.: Cloud Liquid Water
Measurements on the Armored T-28: Intercomparison between Johnson-Williams Cloud Water Meter and CSIRO (King) Liquid Water Probe, J. Atmos. Oceanic Technol., 17, 1630-1638, 2000.

Feingold, G., Furrer, R., Pilewskie, P., Remer, L. A., Min, Q., and Jonsson, H.: Aerosol Indirect Effect Studies at Southern Great Plains during the May 2003 Intensive Operations Period, J. Geophys. Res., 111, D05S14, doi:10.1029/2004JD005648, 2006.

Field, P. R., Wood, R., Brown, P. R. A., Kaye, P. H., Hirst, E., Greenaway, R., and Smith, J. A.: Ice Particle Interarrival Times Measured with a Fast FSSP, J. Atmos. Oceanic Technol., 20, 249-261, 2003.

Field, P. R., Heymsfield, A. J., and Bansemer, A.: Shattering and Particle Interarrival Times Measured by Optical Array Probes in Ice Clouds, J. Atmos. Oceanic Technol., 23, 1357-1371, 2006.

Fountoukis, C., Nenes, A., Meskhidze, N., Bahreini, R., Conant, W. C., Jonsson, H., Murphy, S., Sorooshian, A., Varutbangkul, V., Brechtel, F., Flagan, R. C., and Seinfeld, J. H.: Aerosol-cloud drop concentration closure for clouds sampled during the International Consortium for Atmospheric Research on Transport and Transformation 2004 campaign, J. Geophys. Res., 112, D10S30, doi:10.1029/2006JD007272, 2007.

Gardiner, B. A. and Hallett, J.: Degradation of in-cloud forward scattering spectrometer probe measurements in the presence of ice particles, J. Atmos. Oceanic Technol., 2, 171-180, 1985.

Garrett, T. J. and Zhao, C.: Increased Arctic Cloud Longwave Emissivity Associated with Pollution from Mid-Latitudes, Nature Letters, 440, 787-789, 2006.

Heymsfield, A. J.: On Measurements of Small Ice Particles in Clouds, Geophys. Res. Lett., 34, L23812, doi:10.1029/2007GL030951, 2007.

Hovenac, E. A. and Lock, J. A.: Calibration of the ForwardScattering Spectrometer Probe: Modeling Scattering from a Multimode Laser Beam, J. Atmos. Oceanic Technol., 10, 518-525, 1993.

Jensen, E. J., Lawson, P., Baker, B., Pilson, B., Mo, Q., Heymsfield, A. J., Bansemer, A., Bui, T. P., McGill, M., Hlavka, D., Heymsfield, G., Platnick, S., Arnold, G. T., and Tanelli, S.: On the importance of small ice crystals in tropical anvil cirrus, Atmos. Chem. Phys., 9, 5519-5537, doi:10.5194/acp-9-5519-2009, 2009.

Jonnson, H. and Vonnegut, B.: Technique for Producing Uniform Small Droplets by Capillary Waves Excited in a Meniscus, Rev. Sci. Instrum., 53, 1915-1919, 1982.

King , W. D., Parkin, D. A., and Handsworth, R. J.: A Hot-Wire Liquid Water Device having Fully Calculable Response Characteristics, J. Appl. Meteor., 1809-1813, 1978.

King, W. D., Maher, C. T., and Hepburn, G. A.: Further Performance Tests on the CSIRO Liquid Water Probe, J. Appl. Meteor. 20, 195-202, 1981

King, W. D., Dye, J. E., Strapp, J. W., Baumgardner, D., and Huffman, D.: Icing Wind Tunnel Tests on the CSIRO Liquid Water Probe, J. Oceanic Atmos. Technol, 2, 340-352, 1985.

Knollenberg, R. G.: Practical Applications of Low Power Lasers, SPIE, 92, 137-152, 1976.

Korolev, A. V. and Isaac, G. A.: Shattering During Sampling by OAPs and HVPS. Part I: Snow Particles, J. Atmos. Oceanic Technol., 22, 528-542, 2005.

Korolev, A. V., Makarov, Yu. E., and Novikov, V. S.: On the calibration of photoelectric cloud droplet spectrometer FSSP-100, 
TCAO, 158, 43-49, 1985 (in Russian).

Korolev, A. V., Kuznetsov, S. V., Makarov, Y. E., and Novikov, V. S.: Evaluation of Measurements of Particle Size and Sample Area from Optical Array Probes, J. Atmos. Oceanic Technol., 8, 514-522, 1991.

Korolev, A. V., Emery, E. F., Strapp, J. W., Cober, S. G., Isaac, G. A., Wasey, M., Baker, B., and Lawson, R. P.: Small ice particle observations in tropospheric clouds: fact or artifact?, Airborne Icing Instrumentation Evaluation Experiment, B. Am. Meteor. Soc., in review, 2010.

Lee, E. R.: Microdrop Generation, CRC Press LLC, Boca Raton, FL, 2003.

Lubin, D. and Vogelmann, A. M.: A Climatologically Significant Aerosol Longwave Indirect Effect in the Arctic, Nature, 439, 453-456, doi:10.1038/nature04449, 2006.

McConnell, J. R., Edwards, R. Kok, G. L., Flanner, M. G., Zender, C. S., Saltzman, E. S., Banta, J. R., Pasteris, D. R., Carter, M. M., and Kahl, J. D. W.: 20th-Century Industrial Black Carbon Emissions Altered Arctic Climate Forcing, Science, 317, 13811384, 2007.

McFarquahar, G. M., Um, J., Freer, M., Baumgardner, D., Kok, G. L., and Mace, G.: Importance of Small Ice Crystals to Cirrus Properties: Observations from the Tropical Warm Pool International Cloud Experiment, Geophys. Res. Lett., 34, L13803, doi:10.1029/2007GL029865, 2007.

Meskhidze, N., Nenes, A., Conant, W. C., and Seinfeld, J. H.: Evaluation of a new cloud droplet activation parameterization with in situ data from CRYSTAL-FACE and CSTRIPE, J. Geophys. Res., 110, D16202, doi:10.1029/2004JD005703, 2005.
Nagel, D., Maixner, U., Strapp, W., and Wasey, M.: Advancements in Techniques for Calibration and Characterization of In Situ Optical Particle Measuring Probes, and Applications to the FSSP-100 Probe, J. Atmos. Oceanic Technol., 24, 745-760, doi:10.1175/JTECH2006.1, 2007.

Pinnick, R. G., Garvey, D. M., and Duncan, L. D.: Calibration of Knollenberg FSSP Light-Scattering Counters for Measurement of Cloud Droplets, J. Appl. Meteor., 20, 1049-1057, 1981.

Pruppacher, H. R. and Klett, J. D.: Microphysics of Clouds and Precipitation, 2nd Ed., Kluwer Academic Publishers, the Netherlands, 2000.

Schafer, J., Mondia, J. P., Sharma, R., Lu, Z. H., and Wang, L. J.: Modular Microdrop Generator, Rev. Sci. Instrum., 78, 066102, doi:10.1063/1.2742809, 2007.

Schmidt, S., Lehmann, K., and Wendisch, M.: Minimizing Instrumental Broadening of the Drop Size Distribution with the MFast-FSSP, J. Oceanic Atmos. Technol, 21, 1855-1867, 2004.

Schneider, J. M. and Hendricks, C. D.: Source of Uniform Sized Liquid Droplets. Rev. Sci. Instrum., 35, 1349-1350, 1964.

Seinfeld, J. H. and Pandis, S. N.: Atmospheric Chemistry and Physics, from Air Pollution to Climate Change, John Wiley and Sons, Inc., New York, 1998.

Serreze, M. C. and Francis, J. A.: The Arctic Amplification Debate, Climate Change, 76(3-4), 241-264, 2006.

Wendisch, M., Keil, A., and Korolev, A. V.: FSSP Characterization with Monodisperse Water Droplets, J. Atmos. Oceanic Technol., 13, 1152-1165, 1996. 